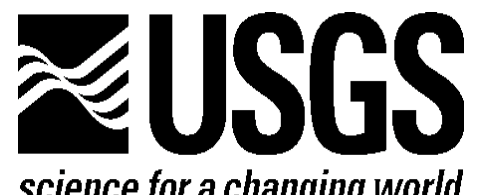

science for a changing world

Prepared for the

Federal Emergency Management Agency, Region 1, and the

Maine Floodplain Management Program, State Planning Office

\title{
Scoping of Flood Hazard Mapping Needs for Kennebec County, Maine
}

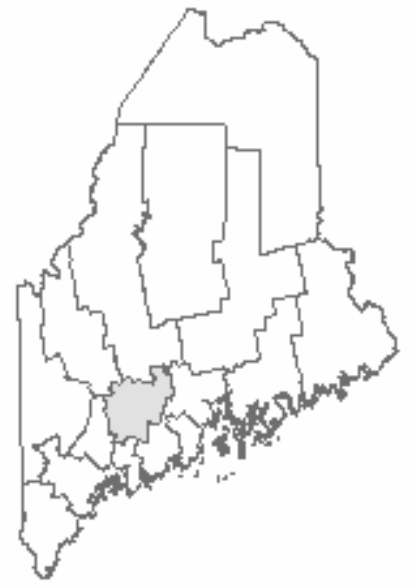

Open-File Report 2006-1099

U.S. Department of the Interior

U.S. Geological Survey

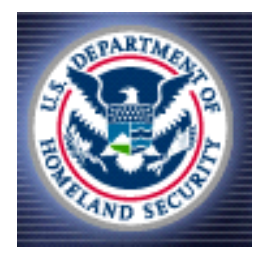


Prepared for the

Federal Emergency Management Agency, Region 1, and the

Maine Floodplain Management Program, State Planning Office

\section{Scoping of Flood Hazard Mapping Needs for Kennebec County, Maine}

By Robert W. Dudley and Charles W. Schalk

Open-File Report 2006-1099

U.S. Department of the Interior

U.S. Geological Survey 


\section{U.S. Department of the Interior \\ Gale A. Norton, Secretary}

U.S. Geological Survey

P. Patrick Leahy, Acting Director

U.S. Geological Survey, Reston, Virginia 2006

For product and ordering information:

World Wide Web: http://www.usgs.gov/pubprod

Telephone: 1-888-ASK-USGS

For more information on the USGS - the Federal source for science about the Earth, its natural and living resources, natural hazards, and the environment:

World Wide Web: http://www.usgs.gov

Telephone: 1-888-ASK-USGS

Suggested citation:

Dudley, R.W., and Schalk, C.W., 2006, Scoping of flood hazard mapping needs for Kennebec County, Maine: U.S. Geological Survey Open-File Report 2006-1099, 120 p.

Any use of trade, product, or firm names is for descriptive purposes only and does not imply endorsement by the U.S. Government.

Although this report is in the public domain, permission must be secured from the individual copyright owners to reproduce any copyrighted material contained within this report. 


\section{Contents}

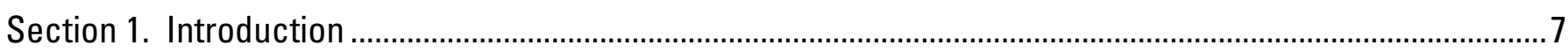

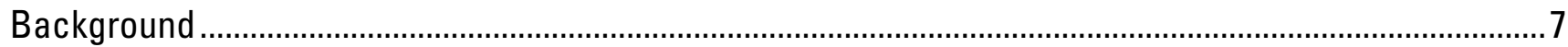

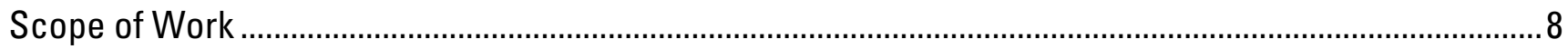

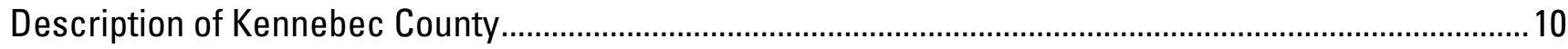

Section 2. Available Flood-Mapping Data and Mapping Needs.................................................................. 13

Community FISs and FIRMs .......................................................................................................... 13

State of Maine Best Available Data (BAD) for Unnumbered A-Zones ....................................................13

Letters of Map Change (LOMCs) ...................................................................................................... 13

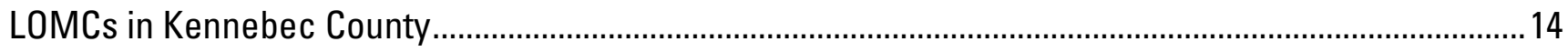

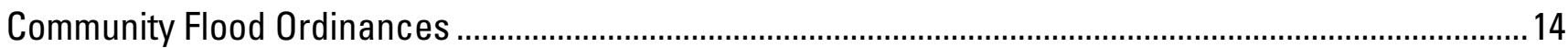

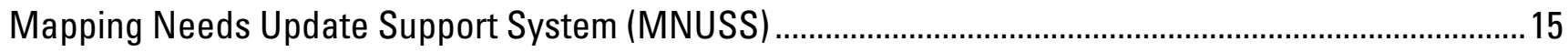

Community Assistance Visits (CAVs) and Community Assessment Contacts (CACs) .............................. 15

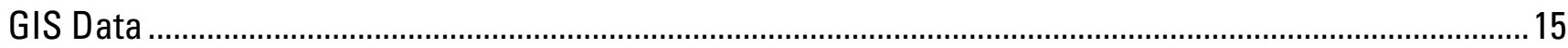

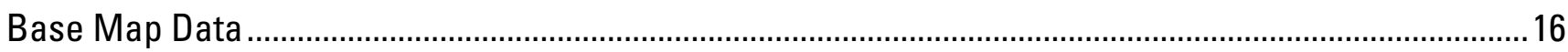

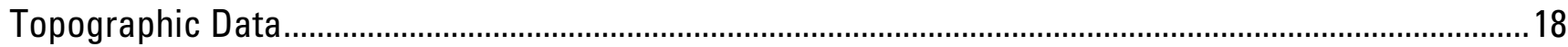

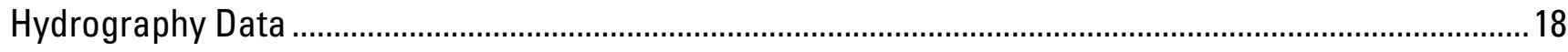

Community GIS Contact Information ........................................................................................... 19

Community Meetings and Contacts.......................................................................................19

Scope and Prioritization of Mapping Needs in Kennebec County ...........................................................20

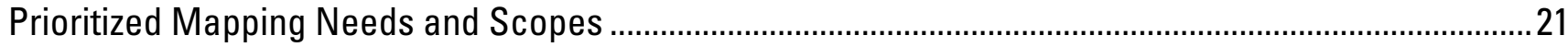

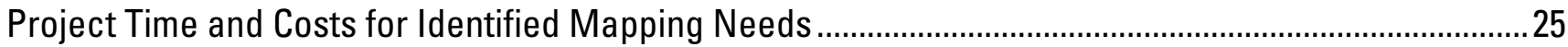

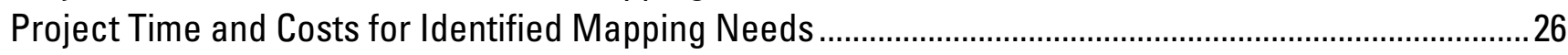

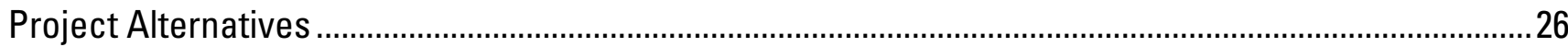

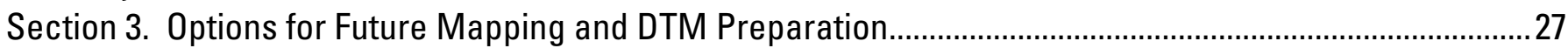

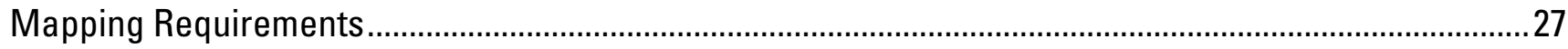

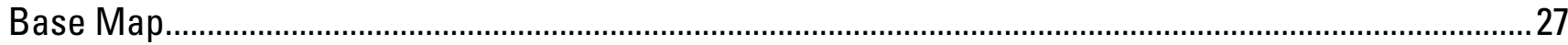

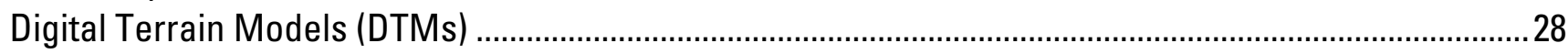

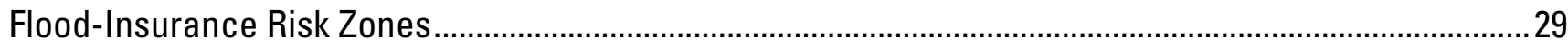

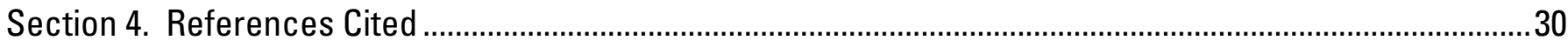

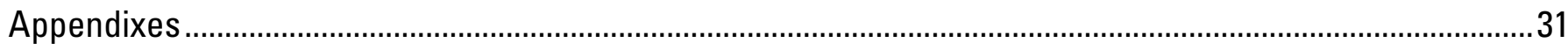

Appendix A: Community Assistance Contacts and Visits: Kennebec County ...............................................32

Appendix B: Community Contacts and Best Available Data: Kennebec County ……………..........................35

Appendix C: Community Scoping Interview Data: Kennebec County............................................................66

Appendix D: Existing MNUSS Data Entries: Kennebec County ………………………...................................77

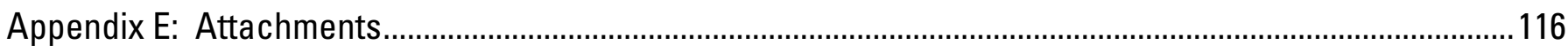




\section{Figures}

1. Communities in Kennebec County, Maine.................................................................................................

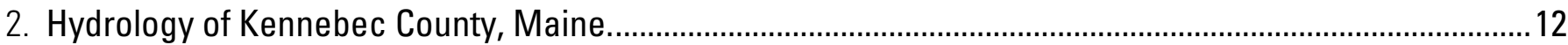

3. Orthophotography indices for Kennebec County, Maine. ………….........................................................17

4. Mapping needs by community in Kennebec County. .................................................................................25

\section{Tables}

1. Organized communities and unorganized territories in Kennebec County, Maine.

2. Maine Floodplain Management Program factors and qualitative weight for prioritization of community-based flood mapping needs in Kennebec County

3. Scoring formula for prioritization of community-based flood mapping needs in Kennebec County...........22

4. Prioritized community-based flood mapping needs in Kennebec County requiring redelineation, limited detail study, or detail study.

5. Prioritized community-based flood mapping need in Kennebec County on the basis of nonrevised baseline-DFIRM production only. 24

6. Flood Insurance Rate Map (FIRM) Horizontal Accuracy...........................................................................28

7. National Standard for Spatial Data Accuracy (NSSDA) ..............................................................................2 
CONVERSION FACTORS AND ABBREVIATIONS

\begin{tabular}{|c|c|c|}
\hline Multiply & By & To obtain \\
\hline \multicolumn{3}{|c|}{ Length } \\
\hline inch (in.) & 25.4 & millimeter (mm) \\
\hline foot (ft) & 0.3048 & meter $(\mathrm{m})$ \\
\hline mile (mi) & 1.609 & kilometer $(\mathrm{km})$ \\
\hline \multicolumn{3}{|c|}{ Area } \\
\hline square foot $\left(\mathrm{ft}^{2}\right)$ & 0.09290 & square meter $\left(\mathrm{m}^{2}\right)$ \\
\hline square mile $\left(\mathrm{mi}^{2}\right)$ & 2.590 & square kilometer $\left(\mathrm{km}^{2}\right)$ \\
\hline \multicolumn{3}{|c|}{ Volume } \\
\hline cubic foot $\left(\mathrm{ft}^{3}\right)$ & 0.02832 & cubic meter $\left(\mathrm{m}^{3}\right)$ \\
\hline \multicolumn{3}{|c|}{ Slope } \\
\hline foot per mile (ft/mi) & 0.1894 & meter per kilometer $(\mathrm{m} / \mathrm{km})$ \\
\hline \multicolumn{3}{|c|}{ Velocity and Flow } \\
\hline foot per second (ft/s) & 0.3048 & meter per second $(\mathrm{m} / \mathrm{s})$ \\
\hline cubic foot per second $\left(\mathrm{ft}^{3} / \mathrm{s}\right)$ & 0.02832 & cubic meter per second $\left(\mathrm{m}^{3} / \mathrm{s}\right)$ \\
\hline
\end{tabular}

OTHER ABBREVIATIONS USED IN REPORT

CAC Community Assistance Contact

CAV Community Assistance Visit

DFIRM Digital Flood Insurance Rate Map

FEMA Federal Emergency Management Agency

FIS Flood Insurance Study

MEGIS Maine Office of Geographic Information Systems

NFIP National Flood Insurance Program

USGS United States Geological Survey 


\section{Scoping of Flood Hazard Mapping Needs for Kennebec County, Maine}

By Robert W. Dudley and Charles W. Schalk

\section{Section 1. Introduction}

This report was prepared by the U.S. Geological Survey (USGS) Maine Water Science Center as the deliverable for scoping of flood hazard mapping needs for Kennebec County, Maine, under Federal Emergency Management Agency (FEMA) Inter-Agency Agreement Number HSFE01-05-X-0018. This section of the report explains the objective of the task and the purpose of the report.

\section{Background}

The Federal Emergency Management Agency (FEMA) developed a plan in 1997 to modernize the FEMA flood mapping program. FEMA flood maps delineate flood hazard areas in support of the National Flood Insurance Program (NFIP). FEMA's plan outlined the steps necessary to update FEMA's flood maps for the nation to a seamless digital format and streamline FEMA's operations in raising public awareness of the importance of the maps and responding to requests to revise them. The modernization of flood maps involves conversion of existing information to digital format and integration of improved flood hazard data as needed. To determine flood mapping modernization needs, FEMA has established specific scoping activities to be done on a county-by-county basis for identifying and prioritizing requisite flood-mapping activities for map modernization. The U.S. Geological Survey (USGS), in cooperation with FEMA and the Maine State Planning Office Floodplain Management Program, began scoping work in 2005 for Kennebec County. Scoping activities included assembling existing data and map needs information for communities in Kennebec County (efforts were made to not duplicate those of pre-scoping completed in March 2005), documentation of data, contacts, community meetings, and prioritized mapping needs in a final scoping report (this document), and updating the Mapping Needs Update Support System (MNUSS) Database or its successor with information gathered during the scoping process.

The average age of the FEMA floodplain maps in Kennebec County, Maine is 16 years. Most of these studies were in the late 1970's to the mid 1980s. However, in the ensuing 20-30 years, development has occurred in many of the watersheds, and the characteristics of the watersheds have changed with time. Therefore, many of the older studies may not depict current conditions nor accurately estimate risk in terms of flood heights. 


\section{Scope of Work}

The following is the scope of work as defined in the FEMA/USGS Statement of Work:

Task 1: Collect data from a variety of sources including community surveys, other Federal and State Agencies, National Flood Insurance Program (NFIP) State Coordinators, Community Assistance Visits (CAVs) and FEMA archives. Lists of mapping needs will be obtained from the MNUSS database, community surveys, and CAVs, if available. FEMA archives will be inventoried for effective FIRM panels, FIS reports, and other flood-hazard data or existing study data. Best available base map information, topographic data, flood-hazard data, and hydrologic and hydraulic data will be identified. Data from the Maine Floodplain Management Program database also will be utilized.

Task 2: Contact communities in Kennebec County to notify them that FEMA and the State have selected them for a map update, and that a project scope will be developed with their input. Topics to be reviewed with the communities include (1) Purpose of the Flood Map Project (for example, the update needs that have prompted the map update); (2) The community's mapping needs; (3) The community's available mapping, hydrologic, hydraulic, and flooding information; (4) target schedule for completing the project; and (5) The community's engineering, planning, and geographic information system (GIS) capabilities.

On the basis of the collected information from Task 1 and community contacts/meetings in Task 2, the USGS will develop a Draft Project Scope for the identified mapping needs of the communities in Kennebec County. The following items will be addressed in the Draft Project Scope: review of available information, determine if and how effective FIS data can be used in new project, and identify other data needed to complete the Project and its source. The Draft Project Scope will establish priority levels for flooding sources to be analyzed and mapped, and estimate schedules and associated costs for completion of the components of flood mapping.

The following subject areas are documented in this report as set forth in the statement of work: available flood-mapping-related data and documented mapping needs, community meetings and contacts, scope and prioritization of mapping needs, and project methods. Scoping-level time and costs for identified mapping needs will be provided as a document separate from this report. The appendix section of this report provides a community by community summary of information obtained and used in the scoping process for all 30 communities in Kennebec County that have Flood Insurance Rate Maps (FIRMs) and (or) Flood Insurance Studies (FISs) (table 1). 
Table 1. Organized communities and unorganized territories in Kennebec County, Maine.

[CID, Community identification number; NSFA, No Specific Flood Hazard Area; FIRM, Flood Insurance Rate Map; *, Community has a published Flood Insurance Study; ${ }^{\circledR}$, Community has a flood insurance rate map largely mapped with unnumbered A-zones but with a water body that has a base flood elevation]

\begin{tabular}{|c|c|c|c|}
\hline Community & CID & $\begin{array}{l}\text { Population } \\
\text { (year 2000) }\end{array}$ & FIRM date \\
\hline Albion, Town of & 230231 & 1,946 & 9/27/1985 \\
\hline Augusta, City of & 230067 & 18,560 & 6/15/1994* \\
\hline Belgrade, Town of & 230232 & 2,978 & $1 / 16 / 1987^{*}$ \\
\hline Benton, Town of & 230233 & 2,557 & $5 / 7 / 2001^{*}$ \\
\hline Chelsea, Town of & 230234 & 2,559 & $6 / 15 / 1994 *$ \\
\hline China, Town of & 230235 & 4,106 & $6 / 5 / 1989 *$ \\
\hline Clinton, Town of & 230236 & 3,340 & $5 / 3 / 1990 *$ \\
\hline Farmingdale, Town of & 230164 & 2,804 & $5 / 2 / 1994 *$ \\
\hline Fayette, Town of & 230237 & 1,040 & $10 / 1 / 2002 *$ \\
\hline Gardiner, City of & 230068 & 6,198 & 7/18/1994* \\
\hline Hallowell, City of & 230069 & 2,467 & 7/18/1994* \\
\hline Litchfield, Town of & 230238 & 3,110 & $11 / 19 / 1986^{*}$ \\
\hline Manchester, Town of & 230239 & 2,465 & $10 / 15 / 1980 *$ \\
\hline Monmouth, Town of & 230240 & 3,785 & 9/3/1980* \\
\hline Mt. Vernon, Town of & 230241 & 1,524 & $9 / 7 / 2001^{\circledR}$ \\
\hline Oakland, Town of & 230242 & 5,959 & $6 / 15 / 1988^{*}$ \\
\hline Pittston, Town of & 230243 & 2,548 & $4 / 6 / 1998 *$ \\
\hline Randolph, Town of & 230244 & 1,911 & $7 / 5 / 1994 *$ \\
\hline Readfield, Town of & 230245 & 2,360 & $12 / 16 / 1980 *$ \\
\hline Rome, Town of & 230246 & 980 & $5 / 17 / 1988^{*}$ \\
\hline Sidney, Town of & 230247 & 3,514 & $11 / 20 / 1998 *$ \\
\hline Unity TWP & 230602 & 31 & NSFHA \\
\hline Vassalboro, Town of & 230248 & 4,047 & 2/7/1975 \\
\hline Vienna, Town of FIRM panels only and study data & 230249 & 527 & $11 / 20 / 1998^{\circledR}$ \\
\hline Waterville, City of & 230070 & 15,605 & $5 / 7 / 2001 *$ \\
\hline Wayne, Town of & 230188 & 1,112 & $4 / 3 / 1989 *$ \\
\hline West Gardiner, Town of & 230250 & 2,902 & $3 / 28 / 1980^{*}$ \\
\hline Windsor, Town of & 230251 & 2,204 & 2/4/1987 \\
\hline Winslow, Town of & 230071 & 7,743 & $5 / 7 / 2001 *$ \\
\hline \multirow[t]{2}{*}{ Winthrop, Town of } & 230072 & 6,232 & $8 / 15 / 1980^{*}$ \\
\hline & TOTAL & 117,114 & \\
\hline
\end{tabular}




\section{Description of Kennebec County}

Kennebec County in south-central Maine (fig. 1) encompasses an area of 940 square miles $\left(\mathrm{mi}^{2}\right)$ and comprises 29 municipalities (towns and (or) cities) and 1 township (table 1, fig. 1). The total population in Kennebec County reported by the 2000 census was approximately 117,000 people. The population for the 2000 census represents a 1-percent increase over the population reported in the 1990 census (115,900 people) and a 6.5-percent increase over the population reported in the 1980 census (109,900 people) (University of Maine, 2004; U.S. Census Bureau, 2002).

There are approximately 223 ponds and lakes in Kennebec County ranging in surface area from 0.11 acres (Unnamed Pond, in Albion) to 8,530 acres $\left(13.3 \mathrm{mi}^{2}\right)$ (Great Pond, in the communities of Belgrade and Rome) for a total surface area of 54,770 acres $\left(85.6 \mathrm{mi}^{2}\right.$ ) (Maine Office of Geographic Information Systems written commun., November 2005). The median pond size is 15.4 acres. There are approximately 1,020 mi of rivers and streams in Kennebec County (fig 2). The largest river in the county, Kennebec River, flows from north to south through the (approximate) middle of the county and through the state capital, Augusta where it has a drainage area of 5,500 $\mathrm{mi}^{2}$ (fig. 2). The Kennebec River composes the corporate boundaries of Waterville, Winslow, Sidney, Vassalboro, Hallowell, Farmingdale, Chelsea, Randolph, Gardiner, and Pittston. Cobbosseecontee Stream, a tributary to the Kennebec River, drains a chain of lakes in Kennebec County including Cobbosseecontee, Annabessacook, and Maranacook Lakes. Messalonskee Stream, a tributary to the Kennebec River, drains a chain of lakes in Kennebec County including Messalonskee Lake, Great Pond, and Long Pond. 


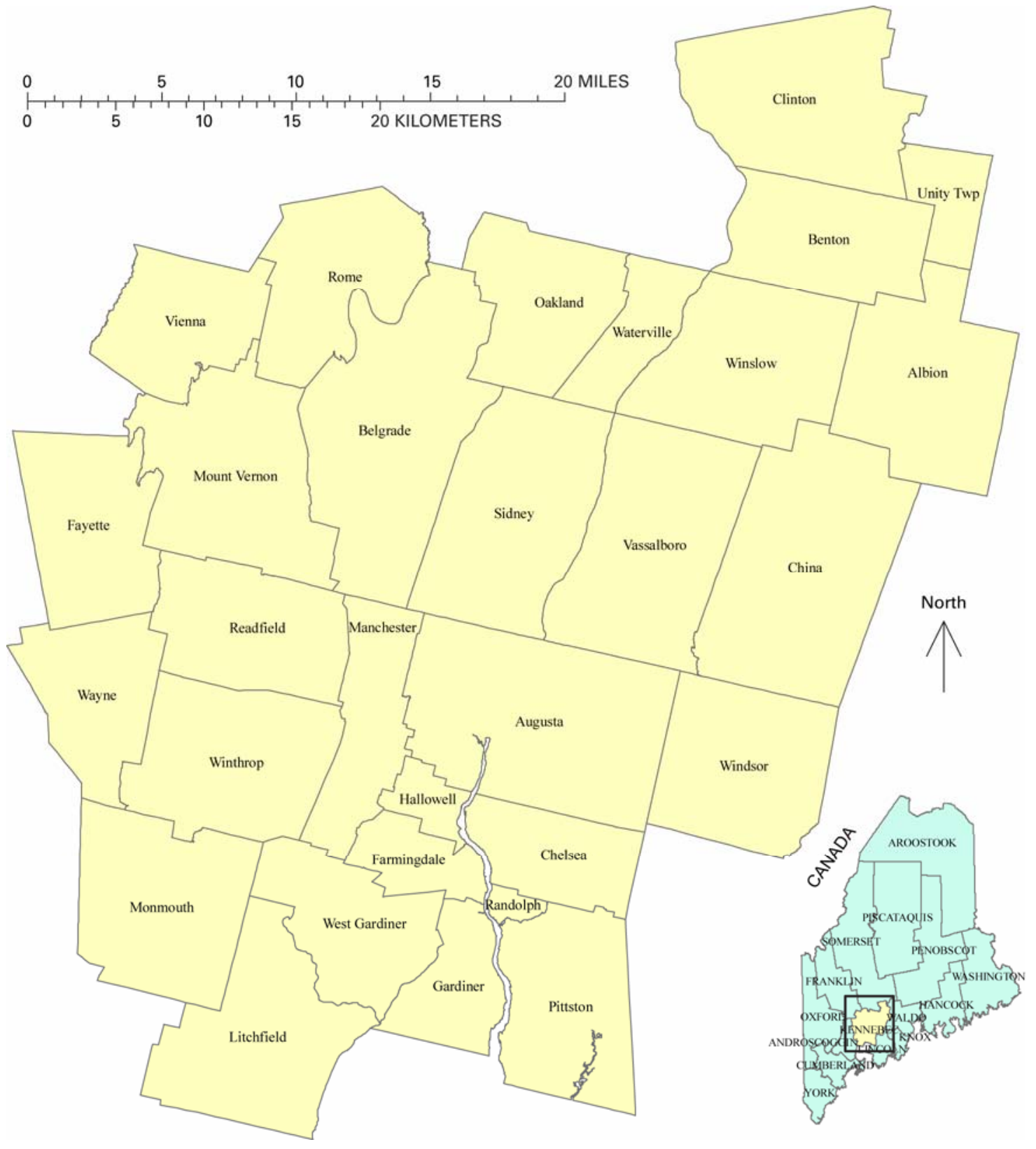

Figure 1. Communities in Kennebec County, Maine. 


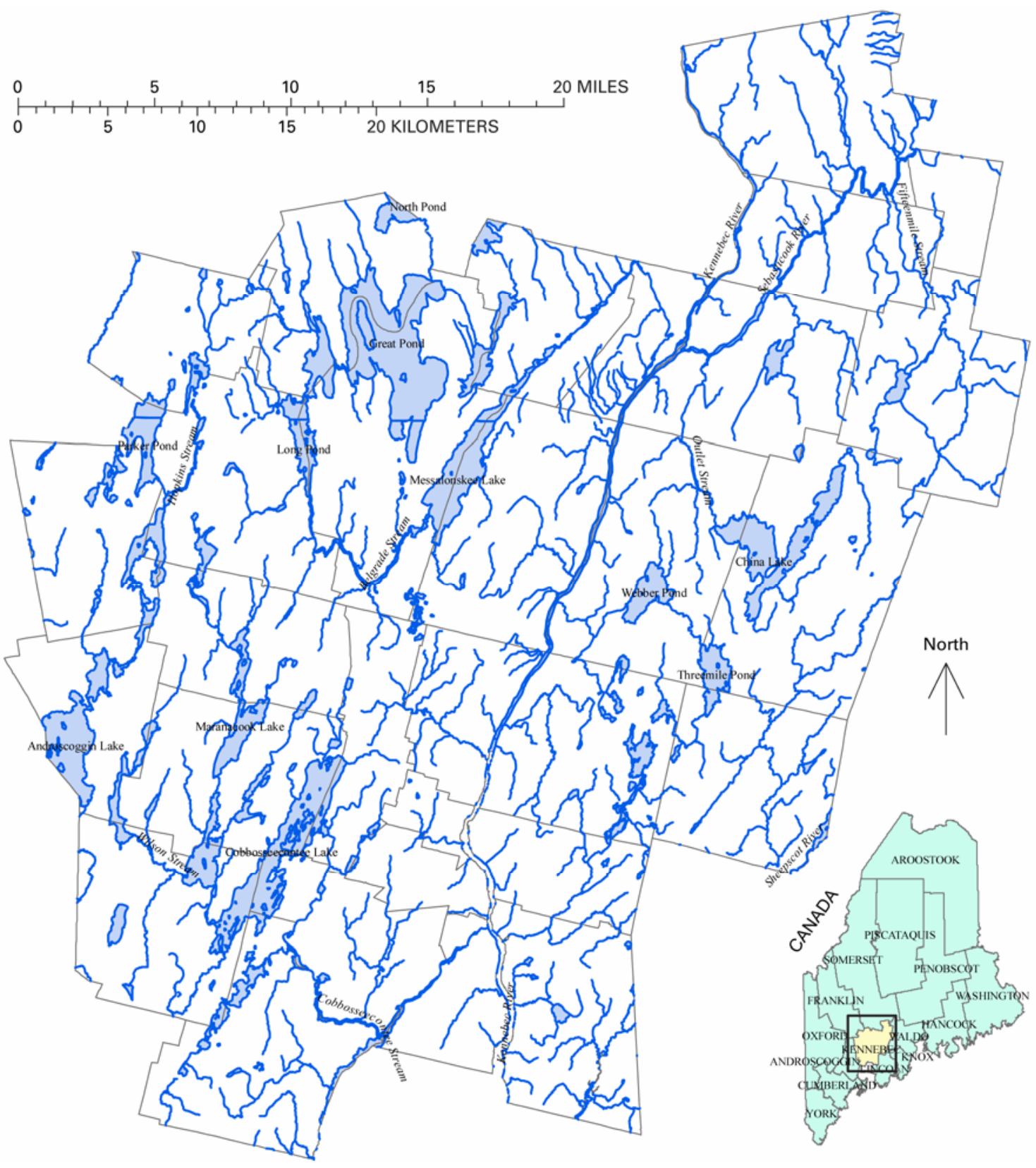

Figure 2. Hydrology of Kennebec County, Maine. 


\section{Section 2. Available Flood-Mapping Data and Mapping Needs}

Flood-mapping data and mapping needs available prior to community scoping meetings were identified in prescoping efforts as part of National Services Provider (NSP) Task Order Number 4 (Burm, 2005). For the scoping activities documented in this report, the USGS reviewed the prescoping report to ensure the data contained in this report is utilized to the maximum extent possible and to avoid duplication of effort.

\section{Community FISs and FIRMs}

There are 23 communities that have FIRMs with active FIS reports in Kennebec county (table 1). Two communities (Towns of Vienna and Mount Vernon) have FIRMS largely mapped with unnumbered A-zones, each with a water body that has a BFE (AE Zone). Four communities (Towns of Albion, Fayette, Vassalboro, Windsor) have FIRMs or Flood-Hazard Boundary Maps with only unnumbered A-zones. One community (Unity Township) is designated as having no specific flood hazard areas (NSFHA) (table 1; Burm, 2005). There are 78 riverine flood profiles for Kennebec County. Communities with FIS reports and communities with unmapped NSFHAs are itemized and flood profiles are summarized by community in the March 2005 Prescoping Report for Kennebec County (Burm, 2005).

The effective map dates range from November 29, 1974, in the town of Fayette to September 7, 2001, in the town of Mount Vernon. Twenty-seven percent of the FIRMs in Kennebec County are 20 years old or older; 73 percent are 10 years or older. The oldest FIRM is 31 years old, the most recent is 4.5 years old, and the average age is approximately 16 years. It is important to note that the effective map date is the date the map was last revised. Some revisions were minor adjustments and did not affect entire map panels. As a result, much of the information depicted on the county's floodplain maps is likely to be older than 16 years.

\section{State of Maine Best Available Data (BAD) for Unnumbered A-Zones}

The Maine Floodplain Management Program has developed, over several years, a data set that tabulates information about the best available data (base flood elevations) for water bodies designated as unnumbered "A" zones on flood maps for communities throughout the State. The base flood elevations tabulated in this data set are derived from hydrologic and (or) hydraulic studies of water bodies that may be published in FISs for adjacent communities or published as part of flood studies not directly related to FEMA FISs (e.g. Army Corps of Engineer projects, Natural Resources Conservation Service projects, and Letter of Map Changes). These data are used in this report as part of the prioritization of mapping needs for a community (see section: Scope and Prioritization of Mapping Needs in Kennebec County). The existence of these data was documented in the March 2005 Prescoping Report for Kennebec County (Burm, 2005) and are documented in the appendix of this

report on a community-by-community basis. Information about these data is available from the Maine Floodplain Management Program web site at: http://www.state.me.us/spo/flood/bad/

\section{Letters of Map Change (LOMCs)}

A Letter of Map Change (LOMC) is a letter issued by FEMA in response to a request to revise or amend an effective National Flood Insurance Program (NFIP) map to remove a property or reflect changed flooding conditions on the effective map. LOMCs may include Letters of Amendments (LOMAs), Letters of Map Revisions (LOMRs), and Letter of Map Revision based on Fill (LOMR-F) as defined below: 
- LOMAs: A LOMA is an official amendment, by letter, to an effective NFIP map. A LOMA establishes the property location in relation to the Special Flood Hazard Area (SFHA). There is no appeal period for LOMAs, and the letter becomes effective the date that it is sent.

- LOMRs: A LOMR is an official revision, by letter, to an effective NFIP map. A LOMR may change flood-insurance risk zones, floodplain and (or) floodway boundary delineations, planimetric features, and (or) Base Flood Elevations (BFEs). The effective date of a LOMR depends on the type of change requested. For example, some LOMR's are effective on the date that the letter is issued and others become effective following an appeal period (typically 30 to 90 days or 6 months).

- LOMR-F: A Letter of Map Revision based on Fill (LOMR-F) may be filed as a special case of the LOMR. A LOMR-F provides FEMA's determination concerning whether a structure or parcel has been elevated on fill above the BFE and excluded from the SFHA. A LOMR-F is an official revision, by letter, to an effective NFIP map. The letter becomes effective on the date that it is sent.

In addition to the categories above, conditional LOMAs, LOMRs, and LOMR-Fs may be issued by FEMA to comment on a proposed project. The letter does not revise an effective NFIP map, but indicates whether the project, if built as proposed, would be recognized by FEMA.

\section{LOMCs in Kennebec County}

The presence and number of LOMCs in a community can be an indication of increasing development in a community and (or) problematic flood hazard boundaries. LOMCs are used in this report as part of the prioritization of mapping needs for a community (see section: Scope and Prioritization of Mapping Needs in Kennebec County). The March 2005 Prescoping Report for Kennebec County (Burm, 2005) tabulates LOMC data for the county. A Geographic Information System (GIS) digital data set representing georeferenced locations of LOMCs within Kennebec County was created as part of the pre-scoping effort.

\section{Community Flood Ordinances}

The Maine Floodplain Management Program provides all participating communities (92 percent of the State's communities) with model floodplain management ordinances, guidance and review, and maintains all community flood ordinances on file. As documented in the March 2005 Prescoping Report for Kennebec County (Burm, 2005), the contact for community flood ordinances is the Maine Floodplain Management Program:

Brigitte Ndikum-Nyada

Planning and Research Associate

Maine Floodplain Management Program

State Planning Office

184 State Street, 38 SHS

Augusta, ME 04333

Tel: 207-287-8932

Fax: 207-287-6489 


\section{Mapping Needs Update Support System (MNUSS)}

In accordance with section 575 of the National Flood Insurance Reform Act of 1994, FEMA assesses "...the need to revise and update all floodplain areas and flood risk zones identified, delineated, or established based on an analysis of all natural hazards affecting flood risks." FEMA initiated the Mapping Needs Assessment (MNA) process, which identifies and prioritizes flood hazard mapping needs for communities nationwide. As part of this effort, FEMA developed the Mapping Needs Update Support System (MNUSS), which is an interactive, web-based software application that maintains an inventory of needs for future map updates. In particular, MNUSS stores information on the following two types of update needs:

- Map Maintenance Needs: Includes changes to base map information, such as the addition of new roads, changes to corporate limits, and incorporation of LOMCs.

- Flood Data Update Needs: Includes changes to flood hazard areas as a result of changes in hydrologic and hydraulic conditions, changes to Base Flood Elevations (BFEs), and (or) changes in the floodplain delineation.

Mapping needs may be viewed and entered into MNUSS by a variety of parties, including FEMA Headquarters and Regional offices, state NFIP coordinators, study contractors, Cooperating Technical Partners (CTPs), and other Federal agencies, such as the U.S. Army Corps of Engineers (USACE) and the USGS. All new or edit needs are reviewed and approved by the FEMA MNUSS controller prior to entry into the system.

The March 2005 Prescoping Report for Kennebec County (Burm, 2005) tabulates MNUSS entries for the county. As part of the scoping process, existing entries in MNUSS were retrieved by USGS and reviewed with the State Planning Office Floodplain Management Program and community representatives. The review process resulted in the identification of duplicate, outdated, missing, and (or) erroneous entries. These findings will provide the basis for updates to MNUSS or its successor upon completion of the scoping report. Existing MNUSS entries are compiled in appendix D.

\section{Community Assistance Visits (CAVs) and Community Assessment Contacts (CACs)}

CAVs and CACs provide assistance to communities regarding the administration and enforcement of their floodplain management ordinances. CAV and CAC data for the county are tabulated in the March 2005 Prescoping Report for Kennebec County (Burm, 2005) and are listed in the appendix of this report (Appendix A).

\section{GIS Data}

Most GIS data in Maine reside with the Maine Office of GIS (MEGIS) as the agency acts as a central repository for these data. Although not every community shares their GIS data with MEGIS, many data sets are shared and served over the Internet. Data can be accessed on the MEGIS web site at: http://apollo.ogis.state.me.us/. Community-specific data that is not shared with MEGIS are documented as part of the community scoping-meeting process (see interview data in Appendix). All data served by MEGIS are referenced to North American Datum 1983 (NAD83), Universal Transverse Mercator (UTM) Zone 19, in meters, and are available to FEMA. 


\section{Base Map Data}

Base map layers maintained by MEGIS include features such as roads, streams, and political boundaries. Base map data layers have been acquired from a variety of sources including the USGS data and represent many of the feature types found on USGS topographic maps. More recently developed data were derived from various sources providing improved base map accuracy. Existing coverages maintained by MEGIS can be linked to or viewed at the following URL:

http://apollo.ogis.state.me.us/

The most detailed orthophotography (0.5-foot resolution) is in the southwestern quadrant of the town of Monmouth (fig. 3); the 0.5 -foot (each image pixel representing a planimetric square 0.5 foot on a side) imagery data set is accurate for $1 "=100$ ' mapping applications and is a true-color mosaic of high-resolution digital orthophotographs. Flown in April 2001, from Portland to Auburn ME the ortho-rectified digital imagery covers nearly all of Cumberland County and part of Androscoggin County. Central Kennebec County is covered by 1 -foot high resolution digital orthophotographs produced from aerial photos collected over southwest Maine in spring 2003 (fig. 3). The remainder of the county is covered by 2-foot resolution digital orthophotographs produced from aerial photos collected over southwest Maine in spring 2003 (fig. 3).

Community-specific aerial photography is documented as part of the community scopingmeeting process (see Appendix). The town of Chelsea indicated that they have black and white aerial photography shot May 13, 1972 at a scale of $1 \mathrm{in}$. equals $400 \mathrm{ft}$. The town of Oakland indicated that they shoot black and white aerial photography of the entire town on an annual basis, scale unspecified. The town of Readfield indicated they have aerial photography from 1998 following the ice storm in January of that year, as well as photography shot in 2003 for GIS use - scale and color formats were unspecified. The town of Winslow indicated they have aerial photography shot in 1993, scale and color format unspecified. 


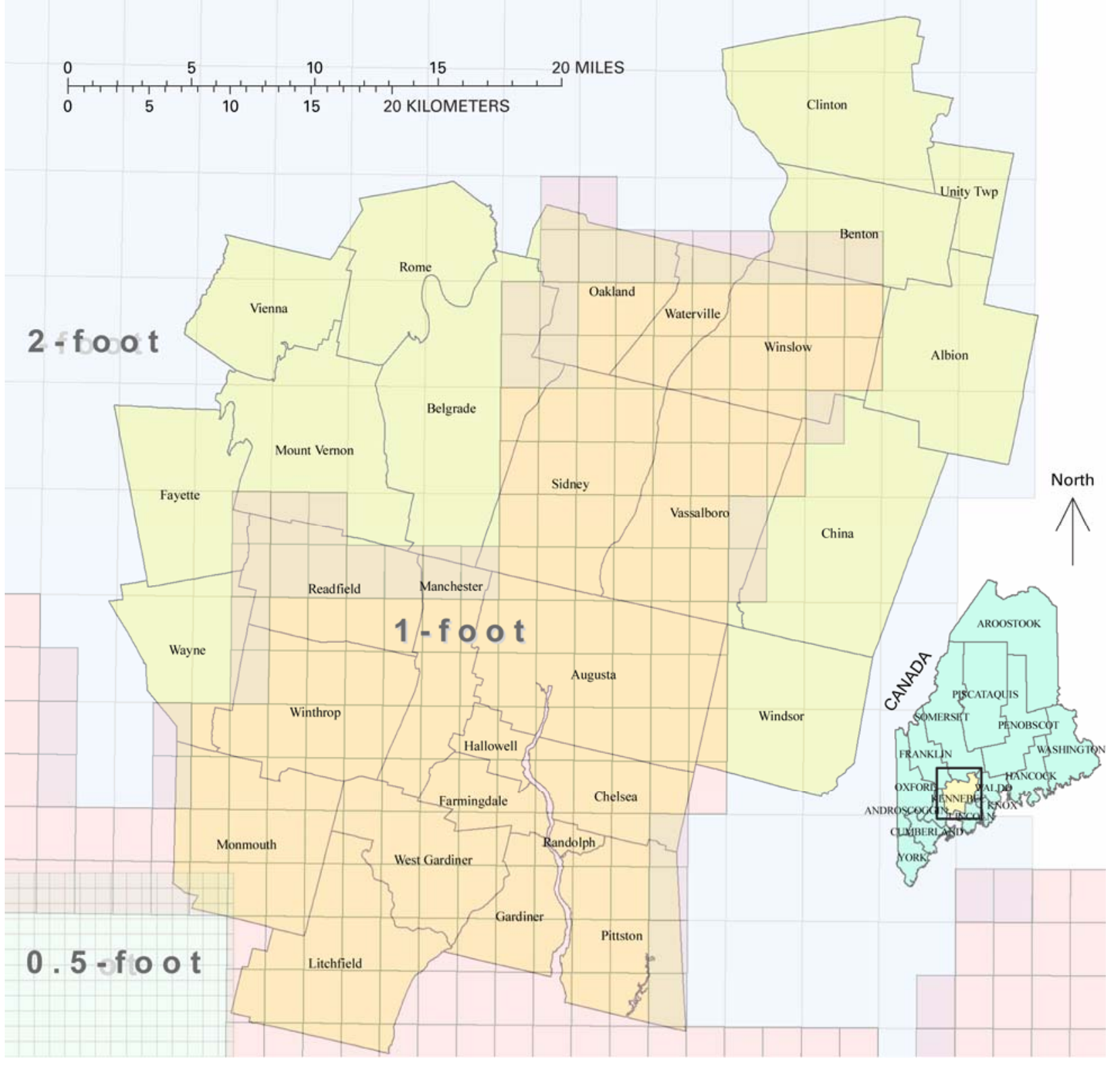

Figure 3. Orthophotography indices for Kennebec County, Maine. Indices indicate coverage of 0.5-foot (each image pixel representing a planimetric square 0.5 foot on a side), 1-foot, and 2-foot orthophotography archived and served through the internet by the Maine Office of Geographic Information Systems (MEGIS). 


\section{Topographic Data}

Digitally scanned USGS 7.5-minute quadrangles provide topographic data for the entire state of Maine with 10- and 20-ft contour intervals, variable by location. Digital Elevation Models (DEM) also are available through the USGS National Elevation Dataset (NED). The NED has been developed by merging the highest-resolution, best quality elevation data available across the United States into a seamless raster format. NED horizontal datum for Maine is NAD83 and vertical datum is North American Vertical Datum 1988 (NAVD88). The NED is continually updated as best available DEM data become available. DEM data with 30 meter $(\mathrm{m})$ resolution (each raster pixel represents a planimetric square 30 meters on a side) are available for the entire state of Maine. DEM data with 10$m$ resolution (1/3 arc second) are available for the entire state of Maine except for extreme northern Somerset and Oxford Counties. DEM data can be downloaded through the USGS Seamless Data Distribution Web site at http://seamless.usgs.gov/web site/seamless/viewer.ph.

The Maine Department of Transportation (MDOT) routinely collects detailed topographic data for highway projects. The data are typically limited to an area within $300 \mathrm{ft}$ of the centerline of the highway. The scope, scale, and accuracy of the data are project specific and depend on the flight level of the survey. MDOT does not maintain any kind of searchable database cataloging these data. The MDOT Survey and Photogrammetric Group is willing to search their files for available data if they are provided a GIS shapefile of an area of interest. As of this draft, MDOT has been provided GIS shapefiles of scoped study areas for Kennebec County. Availability of data is pending. The primary contact for topographic data from the MDOT Survey and Photogrammetric Group is Tim Liseige, Photogrammetric and Control Engineer, (207) 624-3493, tim.liseige@maine.gov.

Community-specific topographic data are documented as part of the community scopingmeeting process (see Appendix). None of the interviewed communities indicated that they had any community-specific topographic data available.

\section{Hydrography Data}

MEGIS, in cooperation with the USGS, is currently enhancing Maine's 1:24,000 digital hydrography data to create National Hydrography Dataset (NHD) high-resolution data (spatial data describing hydrologic features). The NHD data are partitioned into the following layers: streams, ponds, rivers, coast, and National Wetlands Inventory (NWI) data. Progress in this effort is ongoingthe current status of these data can be determined by contacting MEGIS at (207) 624-8800 or by visiting their web site http://apollo.ogis.state.me.us/. NHD data are available for download from the NHD geodatabase at http://nhdgeo.usgs.gov/viewer.htm.

Community-specific hydrography data are documented as part of the community scopingmeeting process (see Appendix). The town of Winslow indicated that Florida Power and Light is doing a study of Halifax Dam as part of the procedures to have it removed. The process to have the Halifax Dam removed is currently ongoing (2006) and there is no guarantee that the dam will be removed. Should it be removed (earliest 2007), this will affect the Sebasticook River FIS for Winslow and upstream perhaps as far as the Benton Falls Dam in Benton; in which case, there will be a need to have this affected reach of river re-studied. 


\section{Community GIS Contact Information}

The March 2005 Prescoping Report for Kennebec County (Burm, 2005) documented the GIS capabilities of communities in Kennebec County. Additional GIS contact information obtained through community scoping meetings is provided in the Appendix on a community by community basis as part of the interview data. The town of Readfield is currently (2006) budgeting for dedicated GIS capabilities. Of all the interviewed communities, only the towns of Winslow and Chelsea indicated that they have dedicated GIS capabilities. Augusta did not attend the meeting but is known to have GIS capabilities by the Maine Floodplain Management Program.

\section{Community Meetings and Contacts}

One community scoping meeting was held for Kennebec County at the USGS Maine Water Science Center in Augusta, Maine, on Monday, November 7th, from 1 to 3 p.m. A second meeting time was planned for November 7th, from 6 to 8 p.m. at the Kennebec Valley Council of Governments (KVCOG) office in Fairfield, Maine, but was cancelled due to lack of interest from town representatives. An invitation letter (with agenda) specifying the time and place and purpose of the meeting was mailed to at least two community officials in every municipality. The letters were addressed to the community code enforcement officer and to the community manager or first selectperson. Planners and surveyors were invited if they were known to the Maine Floodplain Management Program to be involved in floodplain management for their community. Letters were mailed to the Land Use Regulatory Commission (LURC) which oversees land use and other governmental functions for the unorganized territories and townships, and to regional planning commissions, and the county emergency management agency (EMA) director. Example copies of the letter and meeting agenda are attached to this report.

The goals of these meetings were to

- Inform the communities of the nature and the intent of the flood map update process, and

- Solicit community input and discuss the flood-prone areas that communities would like to include as a part of the flood map update.

Robert Dudley, USGS Maine Water Science Center, Bonnie Cowle, Maine Floodplain Management Program, and Stuart Rooney, Watershed Concepts representing FEMA, conducted the meeting. Community representatives were provided an overview of the Map Modernization Program and the map production schedule and technical process.

The latter part of the meeting involved breaking out into small groups with group leaders from USGS, Maine Floodplain Management Program, and Watershed Concepts. The group leaders administered and assisted with the completion of map needs interview forms (example attached, Appendix E). Community representatives were provided copies of their community's flood maps and were encouraged to mark them up as necessary. These marked-up flood maps reside with the Maine Floodplain Management Program. Community representatives were asked to explain and prioritize their needs if possible.

MNUSS entries were reviewed with community representatives for verification. The following two common issues were identified: (1) most MNUSS entries address needs which would be fulfilled with improved base maps such as street locations, street names, and overall difficulty using the map due to lack of distinguishing ground features; and (2) the field indicating "anticipated BFE change" was commonly confused with how much the community thought the BFE was in error - for example, the field may indicate "Increased By 1 to 5 feet" but the need notes may indicate a hydraulic 
structure change that would result in a lower BFE, so in this case the "anticipated BFE change" field is populated with a value of how much the community thinks the BFE is in error rather than how much the BFE is expected to change should the reach be restudied.

During the scoping meetings, the Maine Floodplain Management Program's Best Available Data (BAD) were reviewed with each community representative if BAD data existed for that community. The review was done to make the community aware of the information if they were not already aware of it, and to solicit input on BAD data if any additional information was available to the community that was not listed in the State Planning Office's (SPO) BAD database.

The following three subject areas encompass the data gathered from the scoping meeting process and completion of interview forms: (1) community contact information, (2) areas of the existing flood maps where there are significant problems (poor mapping or development pressures) or changes to hydrologic/hydraulic conditions, and (3) community mapping resources. Communities that did not attend the meetings were sent interview forms, MNUSS entries, and BAD data and asked to review, complete, and return them. The data from the scoping meetings were entered into the watershed information system (WISE) scoping application and are reported for each community in the Appendix as part of the interview data (Appendix B, C, and D).

\section{Scope and Prioritization of Mapping Needs in Kennebec County}

USGS staff (Robert Dudley, Charles Schalk) met with Maine Floodplain Management Program staff (Lou Sidell, Bonnie Cowle) in September 2005 as an initial kick-off meeting for the scoping process. An action item resulting from that meeting involved Maine Floodplain Management Program staff arriving at a list of factors that should be considered for prioritizing potential mapping needs in the county. Table 2 lists the factors and their qualitative weight, as determined by Maine Floodplain Management Program staff, to be considered for prioritization of flood mapping needs in the county.

Table 2. Maine Floodplain Management Program factors and qualitative weight for prioritization of community-based flood mapping needs in Kennebec County.

[Prioritization factors are listed approximately in order from highest to lowest importance; LOMCs, Letters of map change; MNUSS, Mapping needs update support system]

\begin{tabular}{ll}
\hline \multicolumn{1}{c}{ Community Prioritization Factors } & \multicolumn{1}{c}{ Weight } \\
\hline Map age & Very High \\
Map type & Very High \\
Population & High \\
Population growth & High \\
Number of LOMCs & High \\
Number of insurance policies & High \\
Ratio of insurance policies to claims & Medium \\
Presence of best available data & Medium \\
Number of shoreland zoning permits in the vicinity of the water body & Medium \\
Community-specified map needs that coincide with map needs documented in the & Medium to Low \\
Maine Floodplain Management Database and MNUSS & Medium \\
Repetitive loss & \\
\hline
\end{tabular}


Mapping needs were grouped into one of four different types of studies required to create or update flood hazard zones.

- Baseline-DFIRM only: The most economical method of creating a countywide DFIRM is through digitizing flood-hazard information from the effective FIRMs and FISs onto new mapping. This baseline option is currently being undertaken by MEGIS and other FEMA contractors.

- Redelineation: Existing hydrologic and hydraulic studies of the water body are adequate and the water body requires only the redelineation of the base flood elevations using updated topographic data.

- Limited Detailed Study: Automated tools are used to produce digital information or floodmapping for the water body in question has already been studied in detail and requires limited technical reworking of the hydrologic and (or) hydraulic analysis or the water body in question has not been studied in detail but it is expected that approximate methods would suffice to adequately map the flood hazard.

- Detailed Study: Can be performed to develop the digital information, including field surveyed cross-sections and structures. Because this is the most expensive type of study that FEMA can perform, the scope of the detailed study may be limited.

Note that Detail and Limited Detail studies are also assumed to need redelineation using updated topographic data, incorporating results from the new hydrologic and (or) hydraulic analyses.

USGS staff (Robert Dudley, Charles Schalk) met with Maine Floodplain Management Program staff (Bonnie Cowle) December 8, 2005 to review interview data and marked-up maps and to arrive at an initial list of mapping needs for the county. The map needs derived through this meeting were entered into the WISE scoping application. During this meeting, Maine Floodplain Management Program staff provided first-cut prioritization on a scale from 1 to 3 (1=highest) on the basis of community need and historical community involvement in floodplain management.

Other first-cut prioritization factors included BAD, connectivity, and historically documented mapping needs. Higher priority was given to A-zone waterbodies with existing BAD where maps could be created or greatly improved by simply collecting improved topographic information and redelineating existing detailed base flood elevations. Higher priority was given to waterbodies with high connectivity, where connectivity is a measure of the number of neighboring communities that are adjacent to or would otherwise benefit from improved mapping of a particular water body. For example, an A-zone river reach that connected to a detail study upstream or spanned multiple communities or a lake that bordered multiple communities would receive higher priority than a pond contained within the corporate limits of a single community. Higher priority was given to waterbodies that had been historically documented as a mapping need in either the Maine Floodplain Management Program's Database or MNUSS or both. Historical documentation of a mapping need is indicative of an ongoing need that has been known to be a need in the past.

\section{Prioritized Mapping Needs and Scopes}

Mapping needs for the county compiled in consultation with the Maine Floodplain Management Program were ranked on the basis of prioritization scoring factors (table 3). Summing the scoring factors produced a community-based prioritized list of mapping needs involving redelineation, limited detail study, or detail study (table 4, fig. 4). 
A second community-based prioritized list was created for map digitization only (table 5, fig. 4). This second list provides a way to prioritize communities that need modernized maps but do not necessarily have map revision needs (redelineation, limited detail study, or detail study). The scoring formula for this prioritized list used the same factors as those used for table 4 except for presence of BAD, historical mapping needs, water body priority, and water body connectivity.

\section{Table 3. Scoring formula for prioritization of community-based flood mapping needs in Kennebec}

\section{County.}

[Min, minimum data value for the variable of interest; Max, maximum data value for the variable of interest; N/A, not applicable; $\mathrm{mi}^{2}$, square miles; BAD, best available data; LOMCs, letters of map change; Maine Floodplain Management map type codes: $b$, unnumbered A-zones only; $c$, base-flood elevations without floodway; $d$, base- flood elevations with floodway; e, coastal]

\begin{tabular}{|c|c|c|c|c|c|}
\hline \multicolumn{2}{|c|}{ Community population 1} & \multicolumn{2}{|c|}{ Presence of BAD } & \multicolumn{2}{|c|}{$\begin{array}{l}\text { Historical mapping need coincides } \\
\text { with community-specified need }\end{array}$} \\
\hline Range & Score & Range & Score & Range & Score \\
\hline \multirow{2}{*}{$\begin{array}{l}\operatorname{Min}=83 \\
\operatorname{Max}=4,214\end{array}$} & \multirow{2}{*}{$\begin{array}{l}1 \text { point per } 500 \\
\text { people; } \\
\text { maximum of } 50 \\
\text { points }\end{array}$} & Yes & 10 points & Yes & 5 points \\
\hline & & No & 0 & No & 0 \\
\hline \multicolumn{2}{|c|}{ Population Density (people/mi2) } & \multicolumn{2}{|c|}{ Number of insurance policies } & \multicolumn{2}{|c|}{ Number of LOMCs } \\
\hline Range & Score & Range & Score & Range & Score \\
\hline $\begin{array}{l}\operatorname{Min}=4 \\
\operatorname{Max}=89\end{array}$ & $\begin{array}{l}1 \text { point per } 10 \\
\text { people } / \mathrm{mi}^{2} ; \\
\text { maximum of } 50 \\
\text { points }\end{array}$ & $\begin{array}{l}\operatorname{Min}=0 \\
\operatorname{Max}=27\end{array}$ & $\begin{array}{l}1 \text { point per } \\
\text { policy }\end{array}$ & $\begin{array}{l}\operatorname{Min}=0 \\
\operatorname{Max}=42\end{array}$ & $\begin{array}{l}1 \text { point per } \\
\text { LOMC }\end{array}$ \\
\hline \multicolumn{2}{|c|}{ Population Growth2 (percent) } & \multicolumn{2}{|c|}{ Ratio of claims to policies } & \multicolumn{2}{|c|}{ Number of shoreland zoning permits } \\
\hline Range & Score & Range & Score & Range & Score \\
\hline $\begin{array}{l}\operatorname{Min}=-28 \\
\operatorname{Max}=70\end{array}$ & $\begin{array}{l}1 \text { point per } 5 \\
\text { percent (can be } \\
\text { negative) }\end{array}$ & $\begin{array}{l}\operatorname{Min}=0 \\
\operatorname{Max}=1.2\end{array}$ & $\begin{array}{l}5 \text { points } x \text { the } \\
\text { ratio of claims to } \\
\text { policies }\end{array}$ & $\begin{array}{l}\operatorname{Min}=0 \\
\operatorname{Max}=68\end{array}$ & $\begin{array}{l}0.2 \text { point per } \\
\text { shoreland } \\
\text { zoning permit }\end{array}$ \\
\hline \multicolumn{2}{|c|}{ Map age (years) } & \multicolumn{2}{|c|}{ Number of repetitive loss claims } & \multicolumn{2}{|c|}{ Water body connectivity } \\
\hline Range & Score & Range & Score & Range & Score \\
\hline $\begin{array}{l}\operatorname{Min}=10 \\
\operatorname{Max}=21\end{array}$ & 1 point per year & $\begin{array}{l}\operatorname{Min}=0 \\
\operatorname{Max}=2\end{array}$ & $\begin{array}{l}1 \text { point per } \\
\text { repetitive loss } \\
\text { claim }\end{array}$ & $\begin{array}{l}\operatorname{Min}=1 \\
\operatorname{Max}=16\end{array}$ & $\begin{array}{l}1 \text { point per } \\
\text { connected } \\
\text { community }\end{array}$ \\
\hline \multicolumn{2}{|c|}{ Map type } & \multicolumn{2}{|c|}{ Water body priority } & & \\
\hline Range & Score & Range & Score & & \\
\hline $\mathrm{b}$ & 20 points & 1 (highest) & 10 points & & \\
\hline $\mathrm{c}$ & 10 & 2 & 6 & & \\
\hline $\mathrm{d}$ & 5 & 3 (lowest) & 3 & & \\
\hline $\mathrm{e}$ & 5 & & & & \\
\hline
\end{tabular}

${ }^{1}$ On the basis of the 2000 census.

${ }^{2}$ Population growth computed for the period 1980-2000. 
Table 4. Prioritized community-based flood mapping needs in Kennebec County requiring redelineation, limited detail study, or detail study.

\begin{tabular}{|c|c|c|c|c|}
\hline Rank & Water body & Community & Study Type & Score \\
\hline 1 & Kennebec River & Waterville, City of & Limited Detail Study & 132.2 \\
\hline 2 & Patee Pond & Winslow, Town of & Detail Study & 99.9 \\
\hline 3 & Kennebec River & Vassalboro, Town of & Redelineation & 97.9 \\
\hline 4 & Messalonskee Stream & Oakland, Town of & Detail Study & 94.4 \\
\hline 5 & Echo Lake & Fayette, Town of & Redelineation & 91.9 \\
\hline 6 & Three-mile Pond & Windsor, Town of & Redelineation & 83.2 \\
\hline 7 & Maranacook Lake & Readfield, Town of & Redelineation & 82.9 \\
\hline 8 & Outlet Stream & Vassalboro, Town of & Detail Study & 82.9 \\
\hline 9 & Long Pond & Windsor, Town of & Redelineation & 82.2 \\
\hline 10 & Torsey Lake & Readfield, Town of & Limited Detail Study & 75.9 \\
\hline 11 & Flying Pond & Mt. Vernon, Town of & Redelineation & 75.3 \\
\hline 12 & Parker Pond & Mt. Vernon, Town of & Detail Study & 60.3 \\
\hline 13 & Flying Pond & Vienna, Town of & Redelineation & 48.6 \\
\hline 14 & Fifteen-mile Stream & Benton, Town of & Detail Study & 47.0 \\
\hline 15 & Parker Pond & Vienna, Town of & Detail Study & 35.6 \\
\hline
\end{tabular}


Table 5. Prioritized community-based flood mapping need in Kennebec County on the basis of nonrevised baseline-DFIRM production only.

\begin{tabular}{llr}
\hline Rank & & Community \\
\hline 1 & Augusta, City of & 178.0 \\
2 & Gardiner, City of & 143.1 \\
3 & Hallowell, City of & 130.3 \\
4 & Belgrade, Town of & 128.9 \\
5 & Waterville, City of & 112.2 \\
6 & Winthrop, Town of & 106.8 \\
7 & Randolph, Town of & 95.9 \\
8 & Winslow, Town of & 93.9 \\
9 & Litchfield, Town of & 92.0 \\
10 & Oakland, Town of & 87.4 \\
11 & China, Town of & 85.7 \\
12 & Wayne, Town of & 85.4 \\
13 & Monmouth, Town of & 77.3 \\
14 & Vassalboro, Town of & 75.9 \\
15 & West Gardiner, Town of & 75.6 \\
16 & Rome, Town of & 71.9 \\
17 & Fayette, Town of & 68.9 \\
18 & Readfield, Town of & 63.9 \\
19 & Albion, Town of & 63.9 \\
20 & Windsor, Town of & 63.2 \\
21 & Manchester, Town of & 62.8 \\
22 & Mt. Vernon, Town of & 60.3 \\
23 & Farmingdale, Town of & 58.3 \\
24 & Clinton, Town of & 54.0 \\
25 & Sidney, Town of & 53.4 \\
26 & Benton, Town of & 42.0 \\
27 & Chelsea, Town of & 41.8 \\
28 & Pittston, Town of & 31.5 \\
29 & Vienna, Town of & 26.6 \\
30 & Unity TWP & 5.5 \\
\hline & & \\
& & .
\end{tabular}




\section{EXPLANATION}

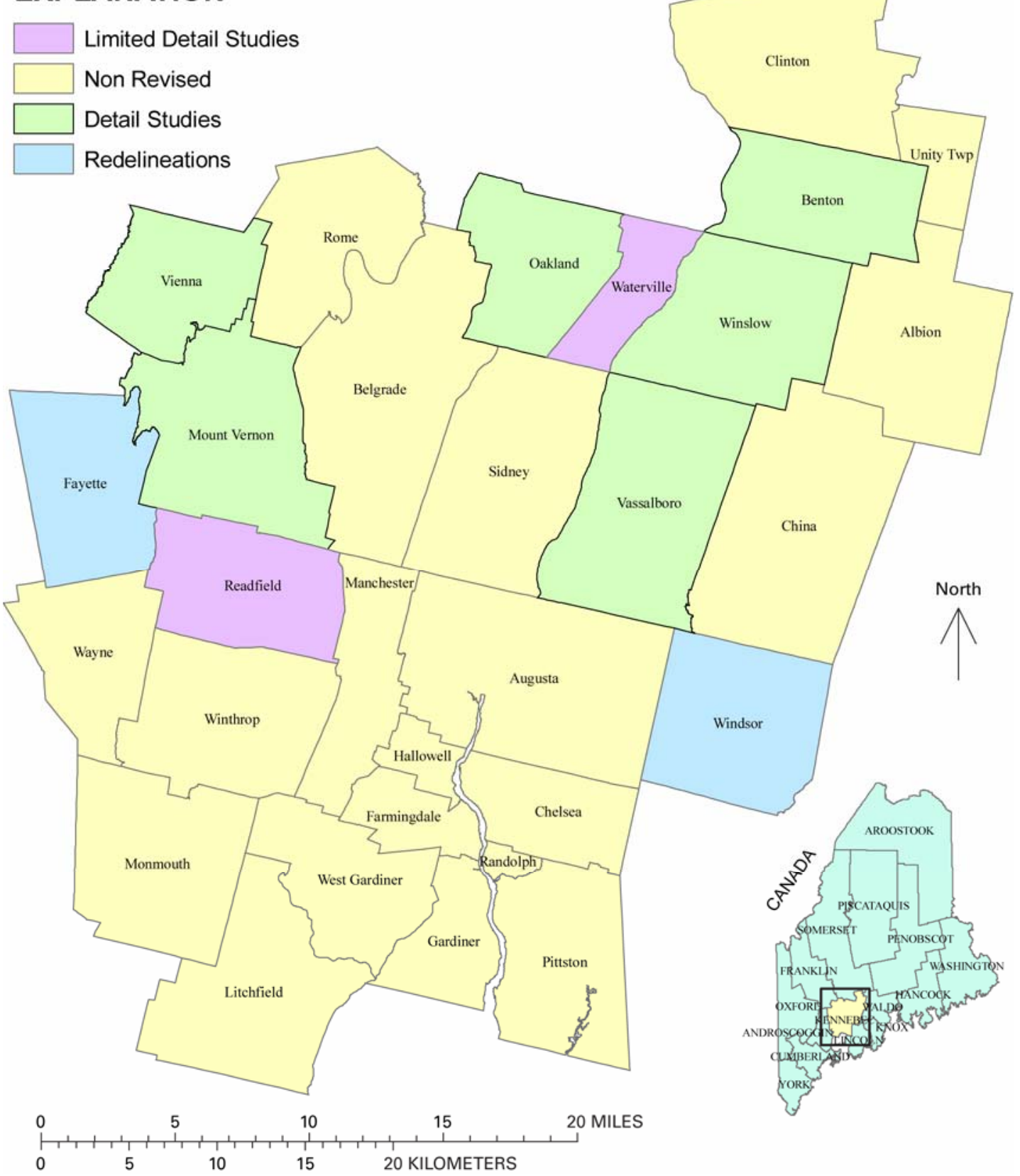

Figure 4. Mapping needs by community in Kennebec County. 


\section{Project Time and Costs for Identified Mapping Needs}

The USGS Maine Water Science Center will provide scoping-level time and cost estimates for the identified study needs for each water body listed in table 4. The time and cost estimates will include costs for hydrologic, hydraulic, and topographic data collection and analyses and mapping, depending on the identified type of study needed for each water body. The time and cost estimates will be submitted to the cooperating agencies (FEMA, Maine Floodplain Management Program) as a separate document as set forth in the scope of work.

\section{Project Alternatives}

Costs can be reduced by cutting back on the level of effort for the hydrologic and hydraulic $(\mathrm{H} \& \mathrm{H})$ analyses and (or) reducing the number of DFIRM panels.

Alternative H\&H options that would help FEMA to reduce costs include reducing the study scope from a detailed study to a limited detail study or redelineation of current flood information only. Reducing the number of DFIRM panels by altering the mix of panel scales would lower the total panel count and reduce the estimated DFIRM production cost. 


\section{Section 3. Options for Future Mapping and DTM Preparation}

\section{Mapping Requirements}

This section provides an assessment of the costs and benefits of utilizing the data cataloged in the previous section for the preparation of Digital Flood Insurance Rate Maps (DFIRMs) for Kennebec County. Options are presented for using these data sets in various combinations and supplementing them with new data sets.

DFIRMs are produced from three broad categories of geospatial data: (1) Base Map, (2) Digital Terrain Model (DTM), and (3) Flood-Insurance Risk Zones. The spatial accuracy of each of these three categories is fixed by the specifications contained in the Guidelines and Specifications for Flood Hazard Mapping Partners, April 2003 (Guidelines and Specifications).

- Base Maps: Base maps are acquired from MEGIS and will be used by FEMA as a "backdrop" to the flood-insurance risk zones shown on the DFIRMs.

- Digital Terrain Models (DTMs): DTMs are used in conjunction with hydrologic and hydraulic models to interpret the limits of flood-insurance risk zones. DTMs represent terrain with irregularly-spaced spot elevations $(\mathrm{x}, \mathrm{y}, \mathrm{z})$ and breaklines that indicate changes in ground slope at features such as the toe or top of channel banks or ridge lines. These data sets are generally photogrametrically compiled by a mapping contractor from stereo photos and utilized in the form of a Triangulated Irregular Network (TIN) or a Digital Elevation Model (DEM). A DEM uses a regular grid, or raster, spacing of $(\mathrm{x}, \mathrm{y}, \mathrm{z})$ points to represent the land surface. Each grid cell is assigned an average elevation to represent the elevation of the ground that is covered by the grid cell. A DEM represents the terrain surface with a mesh of regularly spaced points, whereas a TIN uses contiguous triangular planes.

- Flood-Insurance Risk Zones: Geographic boundaries produced by FEMA and provided in digital format.

\section{Base Map}

Base maps are defined in the Guidelines and Specifications as the "map of the community that depicts cultural features (roads, railroad, bridges, dams, culverts), drainage features, and corporate limits." Depending on the source of the base map, the specific features found on DFIRMs may include the following data and features:

- Roads: centerlines, edge-of-pavement, right-of-way, names.

- Railroads: names.

- Bridges: names.

- Flood Control Structures: headwall, dam, levee, names.

- Airport Boundaries: names.

- Rivers: centerlines, banks, names.

- Streams: names. 
- Lakes: names.

- Political Boundaries: county, municipality, special districts, wards, military reservations, Native American lands, names.

- Land Use: parks, individual land parcels, names.

The Guidelines and Specifications specify "absolute horizontal accuracy" for base map features to establish horizontal accuracy for the position of the digital data set to its actual location on the earth's surface. The horizontal accuracy is specified as a statistical error distribution at the 95percent confidence level and is specified in the Guidelines and Specifications as a function of finished map scale, as shown in table 3-1:

Table 6. Flood Insurance Rate Map (FIRM)

Horizontal Accuracy.

\begin{tabular}{cc}
\hline $\begin{array}{c}\text { [FIRM, Flood Insurance } \\
\text { Rate Map]FIRM map } \\
\text { scale }\end{array}$ & $\begin{array}{c}\text { Absolute horizontal accuracy } \\
\text { at the 95-percent confidence } \\
\text { level, in feet }\end{array}$ \\
\hline 1 in $=500$ feet & 19.0 \\
1 in $=1,000$ feet & 38.0 \\
1 in $=2,000$ feet & 45.6 \\
\hline
\end{tabular}

MEGIS can provide digital data base mapping data for Kennebec County for DFIRM production.

\section{Digital Terrain Models (DTMs)}

FEMA typically develops DTMs for the production of DFIRMS as they are not widely available at the accuracies required by FEMA. The DTMs are used in conjunction with hydrologic and hydraulic models to interpret flood boundaries and can be used by the community for many other purposes other than flood management.

Guidelines and Specifications identify the following four types of DTMs: (1) Digital contours, (2) Digital Elevation Models (DEMs), (3) Mass points and breaklines, and (4) Triangulated Irregular Networks (TIN). Each of these models can be created from the other and their use is application dependent.

Under FEMA guidelines, the allowable DTMs are as follows:

- Digital contours: continuous, nonintersecting lines of equal elevation separated by a specified elevation interval.

- Digital Elevation Model (DTM): $\mathrm{x}, \mathrm{y}$, and $\mathrm{z}$ coordinates of regularly spaced points that form a grid.

- Mass Points and Breaklines: $\mathrm{x}, \mathrm{y}$, and $\mathrm{z}$ coordinates of irregularly spaced points.

- Triangulated Irregular Network (TIN): contiguous triangles with $\mathrm{x}, \mathrm{y}$, and $\mathrm{z}$ values at the vertices and faces with slope and aspect. 
The Guidelines and Specifications specify what is referred to as "absolute vertical accuracy" for DTMs, which relates the elevation of the land surface in the digital data set to its actual elevation relative to a specific vertical datum. The National Standard for Spatial Data Accuracy (NSSDA) is specified as a statistical error distribution at the 90- and 95-percent confidence level as a function of the specified contour interval as shown in table 7:

Table 7. National Standard for Spatial Data Accuracy (NSSDA).

\begin{tabular}{ccc}
\hline $\begin{array}{c}\text { NSSDA Contour } \\
\text { interval }\end{array}$ & $\begin{array}{c}\text { NSSDA 90-percent } \\
\text { confidence interval }\end{array}$ & $\begin{array}{c}\text { NSSDA 95-percent } \\
\text { confidence interval }\end{array}$ \\
\hline 2 feet & 1 foot & 1.2 feet \\
4 feet & 2 feet & 2.4 feet \\
\hline
\end{tabular}

Contouring and DEMs are not printed on DFIRMS so their vertical accuracy is not labeled on the DFIRMS, but it is recorded in the metadata of elevation datasets used for hydrologic and hydraulic modeling.

Neither USGS nor MEGIS has elevation data suitable for hydraulic modeling and communities were contacted to find topographic or elevation data suitable for hydraulic modeling (e.g. 2-foot or 4-foot contours). Community specific topographic data will be used if it meets FEMA standards. New elevation data will be developed as necessary.

DTM development options include (1) obtaining countywide DTM data that covers all communities and (2) obtaining DTM data only for selected floodplain areas as needed to support a detailed study, limited detailed study, restudy or re-delineation of flood hazard areas. Obtaining DTM data on a countywide basis is expensive; most of the acquired data would be outside of the floodplain and not needed for hydraulic analysis. If FEMA obtains new DTM data for selected areas as needed, keeping in mind that is most cost effective to consolidate areas, where possible, and optimizes flights, the unit costs could be reduced.

\section{Flood-Insurance Risk Zones}

Flood-insurance risk zones are created by FEMA to set insurance rates and manage the floodplain. Flood-insurance risk zone accuracy requirements are not specified in the Guidelines and Specifications but can be described in terms of the combined accuracies of the base map, DTM, and the hydrology and hydraulic simulation models.

FEMA flood insurance rate 100- and 500-year flood zones are being converted to digital data layers by MEGIS for each community participating in the National Flood Insurance Program (NFIP) in Maine. These datasets were developed by direct digitization of FIRM maps using data registration techniques that produced the best-fit registration to community boundaries or other suitable features.

The most common comment by community representatives was that a better base map is needed to allow easier determination of where the risk zone boundaries are relative to the existing features such as roads and buildings. 


\section{Section 4. References Cited}

Burm, J.D., 2005, Pre-Scoping Report for Kennebec County, March 2005: Mapping On Demand, NSP Task Order 0004 Deliverable, 70 p.

University of Maine, 2004, Maine census data, population totals: Fogler Library, University of Maine, accessed on September 16, 2004 at http://www.library.umaine.edu/census/

U.S. Census Bureau, 2002, Maine 2000: Summary population and housing characteristics: 2000 Census of Population and Housing, PH-1-21, 275 p. 
Appendixes 
Appendix A: Community Assistance Contacts and Visits: Kennebec County 


\section{Community Assistance Contacts in Kennebec County}

As of 12/2005

ALBION, TOWN OF

Open Date Agency Conducted By Type Closed_Date

$\begin{array}{rrrrr}12 / 12 / 1994 & \text { STATE } & \text { BCB } & \text { PHONE } & 3 / 13 / 1995 \\ 9 / 24 / 2004 & \text { STATE } & \text { SLB } & \text { PHONE } & \end{array}$

BELGRADE, TOWN OF

9/14/1999 STATE SB PHONE 11/29/1999

BENTON, TOWN OF

$\begin{array}{lllll}\text { 9/25/1992 } & \text { STATE } & \text { WLS } & \text { PHONE } & \\ 8 / 30 / 1999 & \text { STATE } & \text { BCB } & \text { PHONE } & \text { 11/29/1999 }\end{array}$

CHELSEA, TOWN OF

9/17/1991 STATE TK PHONE 9/30/1991

CHINA, TOWN OF

$\begin{array}{lllll}\text { 9/22/1992 } & \text { STATE } & \text { TJK } & \text { PHONE } & \text { 9/29/1992 } \\ \text { 8/15/2001 } & \text { STATE } & \text { SB } & \text { PHONE } & \end{array}$

HALLOWELL, CITY OF

8/20/1998 STATE Sb PHONE 1/6/1999

LITCHFIELD, TOWN OF

9/18/1991 STATE TK PHONE 9/30/1991

MANCHESTER, TOWN OF

9/7/1995 STATE BCB PHONE 4/22/1996

MONMOUTH, TOWN OF

$\begin{array}{lllll}\text { 9/21/1992 } & \text { STATE } & \text { TK } & \text { PHONE } & \text { 9/24/1992 } \\ \text { 9/23/1998 } & \text { STATE } & \text { sb } & \text { PHONE } & 6 / 7 / 1999\end{array}$

MT. VERNON, TOWN OF

3/4/1994 STATE TJK PHONE 4/4/1994

OAKLAND, TOWN OF

$\begin{array}{llll}7 / 20 / 1993 & \text { STATE } & \text { TJK } & \text { PHONE } \\ 8 / 31 / 2004 & \text { STATE } & \text { SLB } & \text { PHONE }\end{array}$

PITTSTON, TOWN OF
$6 / 1 / 1994$
STATE TJK
PHONE
8/1/1994

RANDOLPH, TOWN OF

7/26/1994 STATE BCB PHONE 9/13/1994

ROME, TOWN OF

5/12/1994 STATE TJK PHONE




\begin{tabular}{|c|c|c|c|c|c|}
\hline & $\begin{array}{l}\text { Open Date } \\
9 / 27 / 2000\end{array}$ & $\begin{array}{l}\text { Agency } \\
\text { STATE }\end{array}$ & $\begin{array}{l}\text { Conducted By } \\
\text { sue baker }\end{array}$ & $\begin{array}{l}\text { Type } \\
\text { PHONE }\end{array}$ & $\begin{array}{c}\text { Closed_Date } \\
12 / 15 / 200 \odot\end{array}$ \\
\hline \multicolumn{6}{|l|}{ SIDNEY, TOWN OF } \\
\hline & $8 / 15 / 1994$ & STATE & TJK & PHONE & \\
\hline \multicolumn{6}{|l|}{ VIENNA, TOWN OF } \\
\hline & 8/19/1996 & STATE & MB & PHONE & $10 / 22 / 1996$ \\
\hline \multicolumn{6}{|l|}{ WATERVILLE, CITY OF } \\
\hline & $5 / 6 / 1991$ & STATE & TK & PHONE & 5/13/1991 \\
\hline & $6 / 29 / 1993$ & STATE & TJK & PHONE & \\
\hline & $9 / 16 / 1999$ & STATE & SB & PHONE & $11 / 29 / 1999$ \\
\hline \multicolumn{6}{|l|}{ WAYNE, TOWN OF } \\
\hline & $2 / 18 / 2001$ & STATE & Sue baker & PHONE & \\
\hline \multicolumn{6}{|c|}{ WEST GARDINER, TOWN OF } \\
\hline & $5 / 21 / 1991$ & STATE & TK & PHONE & 6/3/1991 \\
\hline \multicolumn{6}{|l|}{ WINDSOR, TOWN OF } \\
\hline & $9 / 27 / 1994$ & STATE & TJK & PHONE & $10 / 20 / 1994$ \\
\hline & $9 / 28 / 2004$ & STATE & SLB & PHONE & \\
\hline \multicolumn{6}{|l|}{ WINTHROP, TOWN OF } \\
\hline & $9 / 26 / 2002$ & STATE & SB & PHONE & \\
\hline
\end{tabular}

\section{Community Assistance Visits in Kennebec County}

As of 12/2005

\begin{tabular}{|c|c|c|c|c|}
\hline \multirow{2}{*}{ AUGUSTA, CITY OF } & Open Date & Agency & Conducted By & Closed_Date \\
\hline & $6 / 29 / 20 \odot 4$ & FEMA & David Kn & \\
\hline \multicolumn{5}{|c|}{ BELGRADE, TOWN OF } \\
\hline & $4 / 23 / 1991$ & STATE & LS & $10 / 17 / 1991$ \\
\hline \multicolumn{5}{|l|}{ CHINA, TOWN OF } \\
\hline & $9 / 16 / 1993$ & STATE & $\mathrm{JD}$ & $3 / 7 / 1994$ \\
\hline \multicolumn{5}{|l|}{ GARDINER, CITY OF } \\
\hline & $9 / 6 / 1993$ & STATE & WLS & \\
\hline \multicolumn{5}{|l|}{ HALLOWELL, CITY OF } \\
\hline & 9/17/1993 & STATE & WLS & $12 / 3 / 1993$ \\
\hline \multicolumn{5}{|c|}{ LITCHFIELD, TOWN OF } \\
\hline & $11 / 26 / 1991$ & STATE & WLS & 9/8/1992 \\
\hline \multicolumn{5}{|c|}{ MANCHESTER, TOWN OF } \\
\hline & $12 / 1 / 200 \odot$ & STATE & Lou Sidell & $2 / 9 / 2001$ \\
\hline \multicolumn{5}{|c|}{ WEST GARDINER, TOWN OF } \\
\hline & $9 / 26 / 1994$ & STATE & WLS & $12 / 8 / 1994$ \\
\hline
\end{tabular}


Appendix B: Community Contacts and Best Available Data: Kennebec County 
COMMUNITY CONTACTS AND BEST AVAILABLE DATA: KENNEBEC COUNTY

\section{Albion, Town of}

Map Type: Unnumbered A-Zone

Participating=Yes LURC: No

Total No. NFIP Policies $=8$

No. Claims Since $1978=0$

$207-437-290 \odot$

Freeland Drake

Selectmen

Town of Albion

PO Box 287

Albion

ME $\quad 04910$

PO Box 22

Unity

ME $\quad 04988$
CID 230231

Community Profile

Ordinance Date: 5/11/1987

All LOMCs: 1

\section{Best Available Data: ND}

Mapping Status: ND

Mapping Needs: ND

ND, No Data; NSFHA, No Specific Flood Hazard Area 
COMMUNITY CONTACTS AND BEST AVAILABLE DATA: KENNEBEC COUNTY

\section{Augusta, City of}

Map Type: Floodways

Participating $=$ Yes LURC: No

Total No. NFIP Policies $=62$ No. Claims Since 1978= 97

William Bridgeo (207) 626-2300

City Manager

City of Augusta

16 Cony St.

Augusta $\quad$ ME 04330

Richard Dolby, CEO

8 Mayflower Rd

Hallowell ME $\quad 04347$

Best Available Data: ND

Mapping Status: ND

Mapping Needs: ND
CID 230067 Community Profile

Current FIRM/FIS Map Date: 6/15/1994

Ordinance Date: 6/20/1994

All LOMCs: 3 
COMMUNITY CONTACTS AND BEST AVAILABLE DATA: KENNEBEC COUNTY

\section{Belgrade, Town of}

CID 230232 Community Profile

Map Type: No Floodways

Current FIRM/FIS Map Date: 1/16/1987

Participating $=$ Yes LURC: No

Ordinance Date: 3/6/1999

Total No. NFIP Policies $=38 \quad$ No. Claims Since 1978= 4

All LOMCs: 30

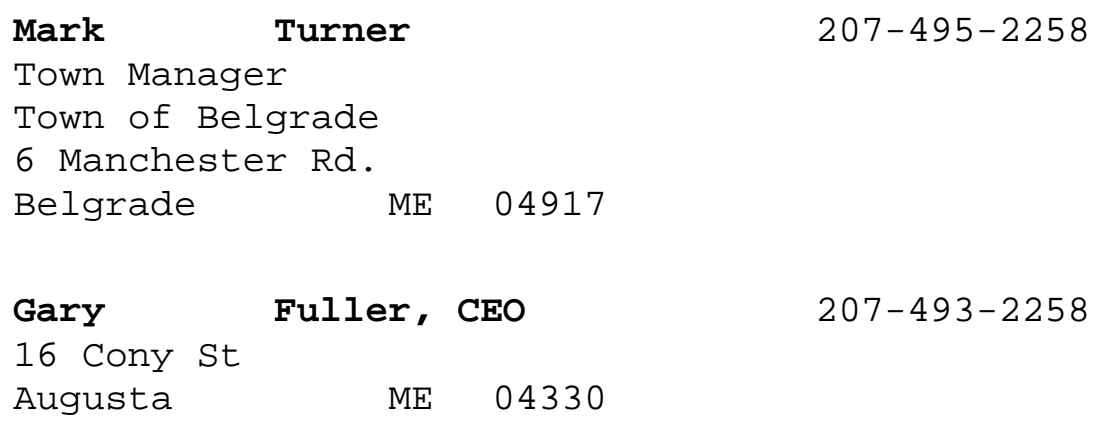

Best Available Data:Barnette Acres, 11-lot subdivision off Wings Mills Rd. on unnamed tributary to Belgrade Stream. A.E. Hodsdon subdivision flood study, 10/99.

Mapping Status: ND

Mapping Needs: ND

ND, No Data; NSFHA, No Specific Flood Hazard Area 
COMMUNITY CONTACTS AND BEST AVAILABLE DATA: KENNEBEC COUNTY

\section{Benton, Town of}

Map Type: Floodways

Participating $=$ Yes LURC: No

Total No. NFIP Policies $=3$

No. Claims Since 1978= 7

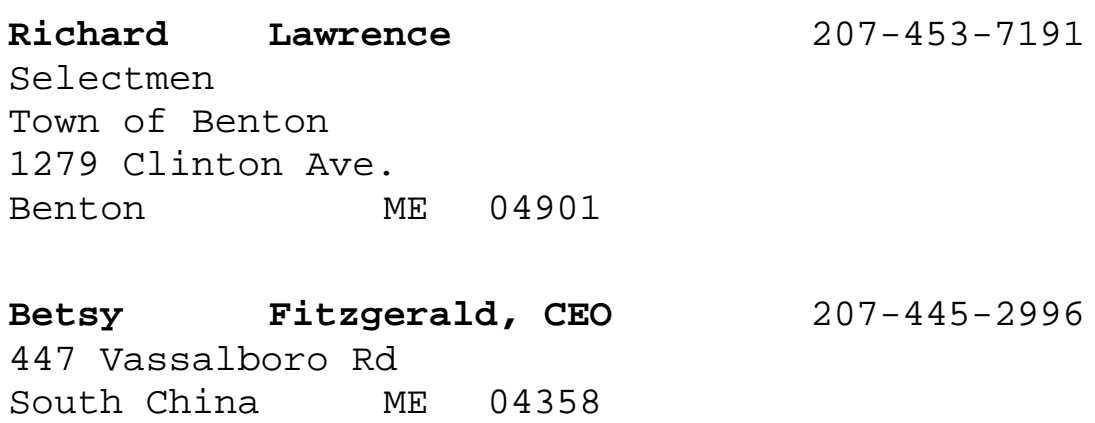

Best Available Data: ND

Mapping Status: ND

Mapping Needs: ND
CID 230233 Community Profile

Current FIRM/FIS Map Date: 5/7/2001

Ordinance Date: 3/10/2001

All LOMCs: $\odot$ 
COMMUNITY CONTACTS AND BEST AVAILABLE DATA: KENNEBEC COUNTY

\section{Chelsea, Town of}

Map Type: Floodways

Participating=Yes LURC: No

Total No. NFIP Policies $=1$

No. Claims Since $1978=1$

Robert Drisko

Town Manager

Town of Chelsea

560 Togus Rd.

Chelsea

ME $\quad 04330$

Robert St. Pierre, Sr., CEO 207-582-4802

Rt. 9 Box 1320

Chelsea

ME $\quad 04330$
CID 230234

Community Profile

Ordinance Date: 6/28/1994

All LOMCs: $\odot$

Best Available Data: ND

Mapping Status: ND

Mapping Needs: ND

ND, No Data; NSFHA, No Specific Flood Hazard Area 
COMMUNITY CONTACTS AND BEST AVAILABLE DATA: KENNEBEC COUNTY

\section{China, Town of}

Map Type: No Floodways

Participating $=$ Yes LURC: No

Total No. NFIP Policies $=19$

No. Claims Since 1978= 3
CID 230235

Community Profile

Ordinance Date: 4/11/1990

All LOMCs: 15

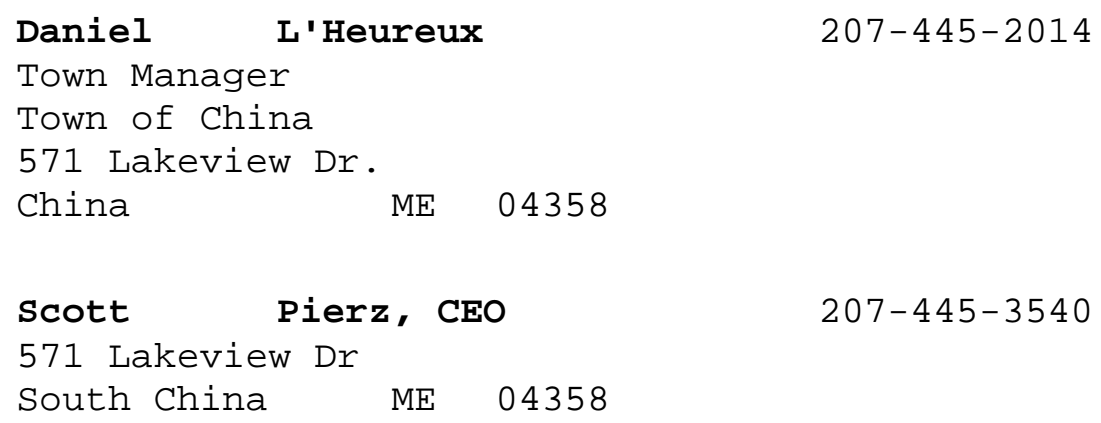

Best Available Data: ND

Mapping Status: D\&D will look at for XDS projects in '97/'98. (didn't happen)

Mapping Needs: Refer to Map File:

Discrepancy in map corporate limits between the towns of China and Vassalboro. The correct corporate limits is

along the western shore of Three Mile Pond, shown in 2/7/75

Flood Hazard Boundary Map for the town of Vassalboro. FIRM Panel 0005 B needs to be revised.

ND, No Data; NSFHA, No Specific Flood Hazard Area 
COMMUNITY CONTACTS AND BEST AVAILABLE DATA: KENNEBEC COUNTY

\section{Clinton, Town of}

Map Type: Floodways

Participating $=$ Yes LURC: No

Total No. NFIP Policies $=6$

No. Claims Since 1978= 8

D. Dwight Dogherty

Town Manager

Town of Clinton

PO Box 219

Clinton

ME $\quad 04927$

Kenneth Hogate, CEO

161 West Ridge Rd

Cornville ME 04976

Best Available Data: ND

Mapping Status: ND

Mapping Needs: ND
CID 230236 Community Profile

Current FIRM/FIS Map Date: 5/3/1990

Ordinance Date: $3 / 10 / 1990$

All LOMCs: $\odot$

$207-426-8511$

$207-426-8511$ 
COMMUNITY CONTACTS AND BEST AVAILABLE DATA: KENNEBEC COUNTY

\section{Farmingdale, Town of}

CID 230164

Community Profile

Map Type: Floodways

Current FIRM/FIS Map Date: 5/2/1994

Participating=Yes LURC: No

Ordinance Date: 3/9/1994

Total No. NFIP Policies $=7$

No. Claims Since $1978=3$

All LOMCs: $\odot$

Phyllis Weeks 207-582-2225

Selectmen

Town of Farmingdale

289 Maine Ave.

Farmingdale ME 04344

Robert St. Pierre, Sr., CEO 207-582-4802

Rt. 9 Box 1320

Chelsea

ME $\quad 04330$

Best Available Data: ND

Mapping Status: ND

Mapping Needs: ND

ND, No Data; NSFHA, No Specific Flood Hazard Area 
COMMUNITY CONTACTS AND BEST AVAILABLE DATA: KENNEBEC COUNTY

\section{Fayette, Town of}

Map Type: Unnumbered A-Zone

Participating $=$ Yes LURC: No

Total No. NFIP Policies=ND No. Claims Since 1978= ND

Mark Robinson 207-685-4373

Town Manager

Town of Fayette

Rte 17, 2589 Main St.

Fayette

ME $\quad 04349$

PO Box 182

Readfield

ME $\quad 04355$
CID 230237

Community Profile

Ordinance Date: 6/19/1999

All LOMCs: $\odot$

Best Available Data: Lovejoy Pond: Bfe 305' (Wayne FIS 4/3/89)

Mapping Status: ND

Mapping Needs: ND

ND, No Data; NSFHA, No Specific Flood Hazard Area 
COMMUNITY CONTACTS AND BEST AVAILABLE DATA: KENNEBEC COUNTY

\section{Gardiner, City of}

CID 230068

Community Profile

Map Type: Floodways

Current FIRM/FIS Map Date: 7/18/1994

Participating=Yes LURC: No

Ordinance Date: 6/28/2003

Total No. NFIP Policies $=48$

No. Claims Since $1978=79$

All LOMCs: $\odot$

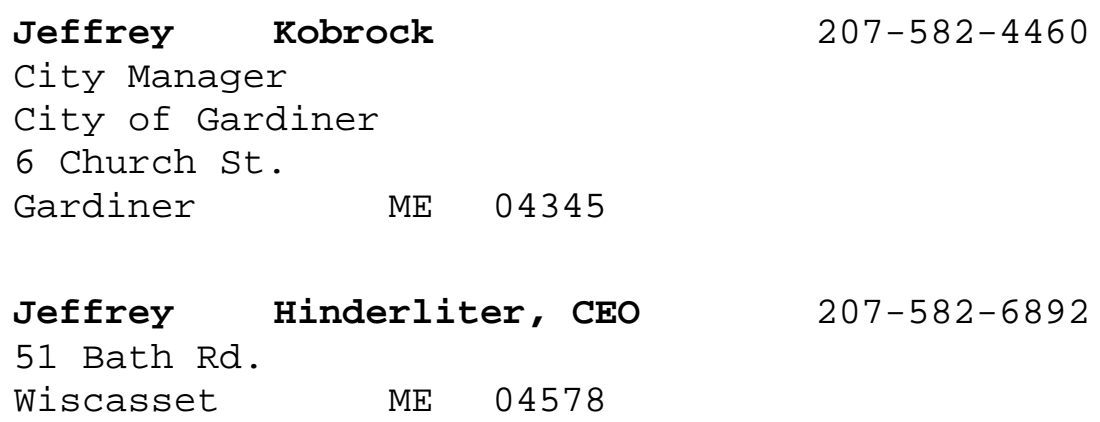

Best Available Data: ND

Mapping Status: ND

Mapping Needs: ND

ND, No Data; NSFHA, No Specific Flood Hazard Area 
COMMUNITY CONTACTS AND BEST AVAILABLE DATA: KENNEBEC COUNTY

\section{Hallowell, City of}

CID 230069 Community Profile

Map Type: Floodways

Current FIRM/FIS Map Date: 7/18/1994

Participating $=$ Yes LURC: No

Ordinance Date: 12/8/2003

Total No. NFIP Policies $=43 \quad$ No. Claims Since 1978 $=47$

All LOMCs: 1

\begin{tabular}{|c|c|c|c|}
\hline James & Rhodes & & $207-623-4021$ \\
\hline City Manage & & & \\
\hline City of $\mathrm{Ha}$ & lowell & & \\
\hline 1 Winthrop & St. & & \\
\hline Hallowell & ME & 04347 & \\
\hline avid & Giroux, & CEO & $207-685-4373$ \\
\hline O Box 182 & & & \\
\hline eadfield & ME & 04355 & \\
\hline
\end{tabular}

Best Available Data: ND

Mapping Status: ND

Mapping Needs: ND

ND, No Data; NSFHA, No Specific Flood Hazard Area 
COMMUNITY CONTACTS AND BEST AVAILABLE DATA: KENNEBEC COUNTY

\section{Litchfield, Town of}

CID 230238

Community Profile

Map Type: Floodways

Current FIRM/FIS Map Date: 11/19/1986

Participating=Yes LURC: No

Ordinance Date: 6/13/1992

Total No. NFIP Policies $=19$ No. Claims Since 1978= 2

All LOMCs: 10

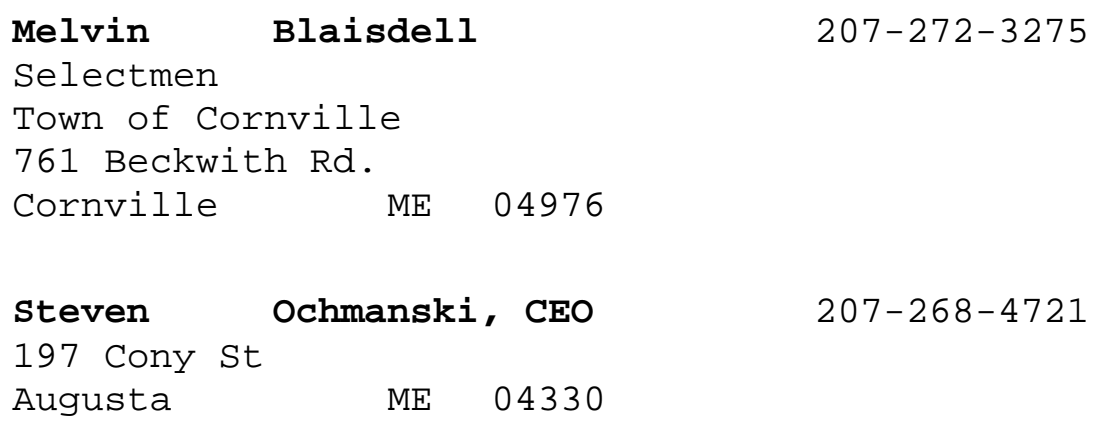

Best Available Data: ND

Mapping Status: ND

Mapping Needs: ND

ND, No Data; NSFHA, No Specific Flood Hazard Area 
COMMUNITY CONTACTS AND BEST AVAILABLE DATA: KENNEBEC COUNTY

\section{Manchester, Town of}

Map Type: Floodways

Participating $=$ Yes LURC: No

Total No. NFIP Policies $=9$

No. Claims Since $1978=0$

Mark Doyon

Town Manager

Town of Manchester

PO Box 18

Manchstester ME 04351

Steven Ochmanski, CEO 207-268-4721

197 Cony St

Augusta $\quad$ ME $\quad 04330$

Best Available Data: ND

Mapping Status: ND

Mapping Needs: see letter from town dated 5/21/97

$207-622-1894$
CID $230239 \quad$ Community Profile

Current FIRM/FIS Map Date: 10/15/1980

Ordinance Date: 6/11/2001

All LOMCs: 2 
COMMUNITY CONTACTS AND BEST AVAILABLE DATA: KENNEBEC COUNTY

\section{Monmouth, Town of}

Map Type: No Floodways

Participating $=$ Yes LURC: No

Total No. NFIP Policies $=12$ No. Claims Since 1978= 5

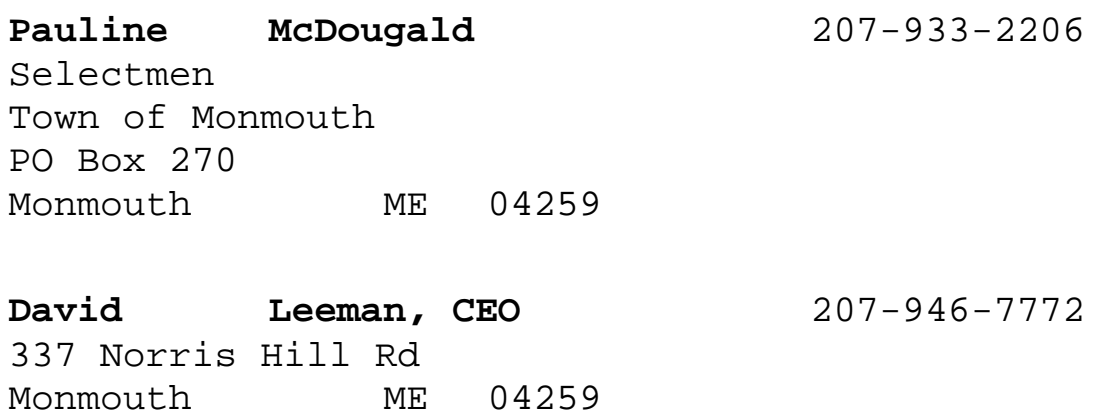

Best Available Data: ND

Mapping Status: ND

Mapping Needs: ND
CID 230240

Community Profile

Current FIRM/FIS Map Date: 9/3/1980

Ordinance Date: 4/28/1998

All LOMCs: 4 
COMMUNITY CONTACTS AND BEST AVAILABLE DATA: KENNEBEC COUNTY

Mt. Vernon, Town of

Map Type: No Floodways

Participating=Yes LURC: No

Total No. NFIP Policies $=11$ No. Claims Since 1978= $\odot$

Denise Williams 207-293-2379

Selectmen

Town of Mt. Vernon

1997 North Rd.

Mt. Vernon ME 04352

Richard Marble, CEO 207-293-2636

853 Holley Rd

Farmington ME 04938

Best Available Data: ND

Mapping Status: ND

Mapping Needs: ND
CID $230241 \quad$ Community Profile

Current FIRM/FIS Map Date: 9/7/2001

Ordinance Date: 9/5/2001

All LOMCs: 9 
COMMUNITY CONTACTS AND BEST AVAILABLE DATA: KENNEBEC COUNTY

\section{Oakland, Town of}

CID 230242

Community Profile

Map Type: No Floodways

Current FIRM/FIS Map Date: 6/15/1988

Participating $=$ Yes LURC: No

Ordinance Date: 11/10/2004

Total No. NFIP Policies $=4$

No. Claims Since $1978=0$

All LOMCs: $\odot$

Steven Dyer

$207-465-7357$

Town Manager

Town of Oakland

PO Box 187

Oakland ME 04963

Robert Ellis, CEO 207-465-2842

P.0. Box 187

Oakland

ME $\quad 04963$

Best Available Data: ND

Mapping Status: ND

Mapping Needs: ND

ND, No Data; NSFHA, No Specific Flood Hazard Area 
COMMUNITY CONTACTS AND BEST AVAILABLE DATA: KENNEBEC COUNTY

\section{Pittston, Town of}

Map Type: Floodways

Participating $=$ Yes LURC: No

Total No. NFIP Policies $=3$

No. Claims Since $1978=\odot$

$207-582-4438$

Arlene Shea

Selectmen

Town of Pittston

Rte 126, RR 2, Box 9A

Gardiner

ME $\odot 4345$

Ernest Martin, Sr., CEO

Rt 4 Bx7938 Mast Rd.

Gardiner ME 04345

Best Available Data: ND

Mapping Status: ND

Mapping Needs: ND
CID 230243 Community Profile

Current FIRM/FIS Map Date: 4/6/1998

Ordinance Date: 6/30/1998

All LOMCs: $\odot$ 
COMMUNITY CONTACTS AND BEST AVAILABLE DATA: KENNEBEC COUNTY

\section{Randolph, Town of}

Map Type: Floodways

Participating=Yes LURC: No

Total No. NFIP Policies $=22$ No. Claims Since 1978= 9

R. Gloria Fitzherbert 207-582-5808

Selectmen

Town of Randolph

121 Kinderhook St.

Randolph ME 04346

Robert St. Pierre, Sr., CEO 207-582-4802

Rt. 9 Box 1320

Chelsea ME 04330

Best Available Data: ND

Mapping Status: ND

Mapping Needs: ND
CID 230244 Community Profile

Current FIRM/FIS Map Date: 7/5/1994

Ordinance Date: 6/2/1994

All LOMCs: $\odot$ 
COMMUNITY CONTACTS AND BEST AVAILABLE DATA: KENNEBEC COUNTY

\section{Readfield, Town of}

CID 230245

Community Profile

Map Type: No Floodways

Current FIRM/FIS Map Date: 12/16/1980

Participating=Yes LURC: No

Ordinance Date: 2/10/1997

Total No. NFIP Policies $=6$

No. Claims Since $1978=0$

All LOMCs: 2

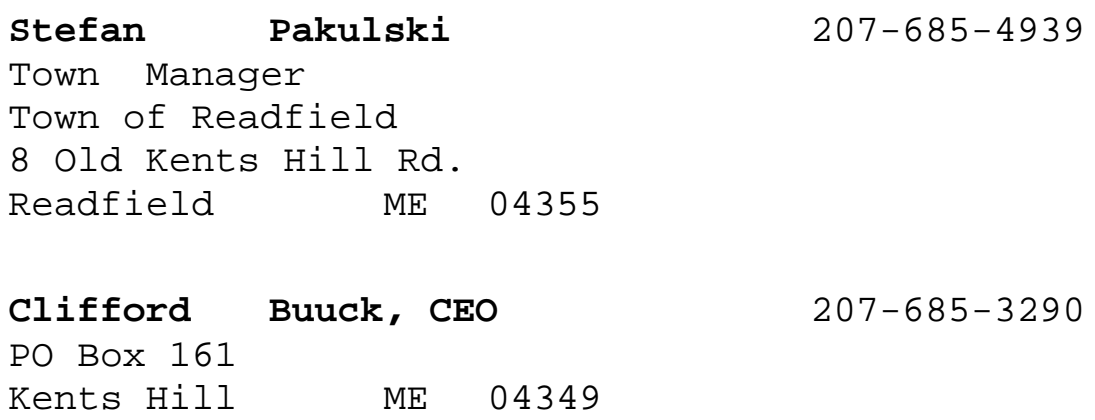

Best Available Data: ND

Mapping Status: ND

Mapping Needs: ND

ND, No Data; NSFHA, No Specific Flood Hazard Area 
COMMUNITY CONTACTS AND BEST AVAILABLE DATA: KENNEBEC COUNTY

\section{Rome, Town of}

Map Type: No Floodways

Participating $=$ Yes LURC: No

Total No. NFIP Policies $=9$
CID 230246

Community Profile
Current FIRM/FIS Map Date: 5/17/1988

Ordinance Date: 3/9/2002

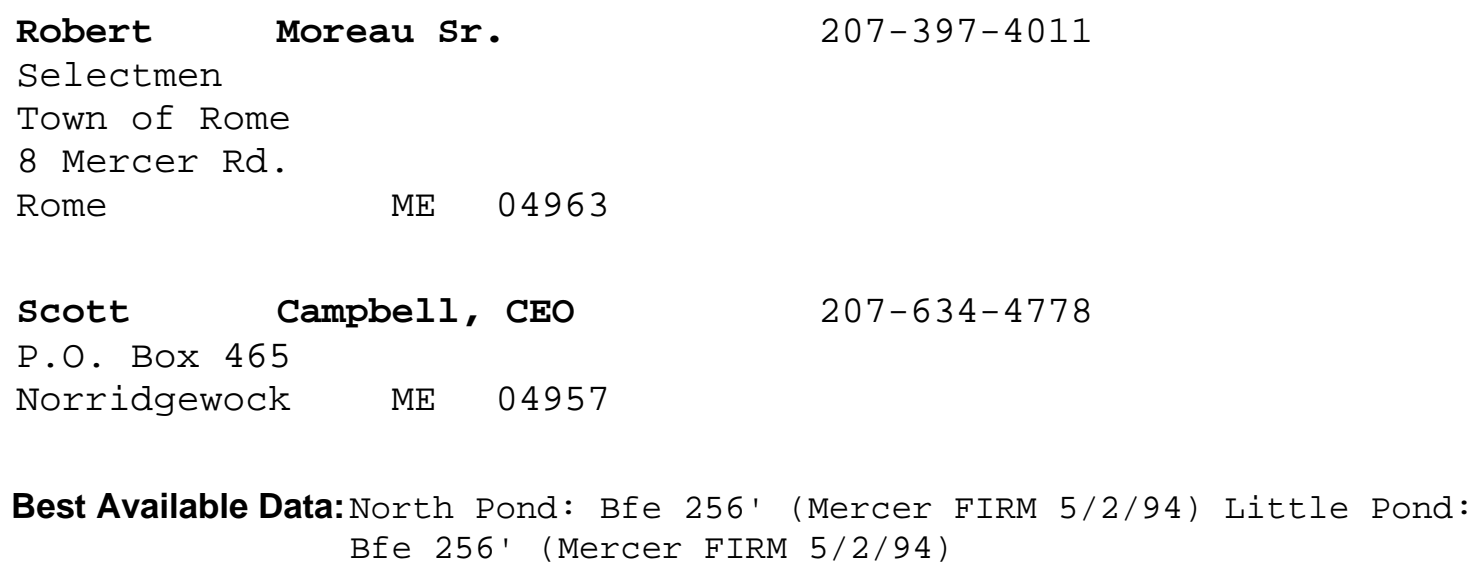

Mapping Status: ND

Mapping Needs: ND 
COMMUNITY CONTACTS AND BEST AVAILABLE DATA: KENNEBEC COUNTY

\section{Sidney, Town of}

Map Type: No Floodways

Participating=Yes LURC: No

Total No. NFIP Policies=ND No. Claims Since 1978= ND

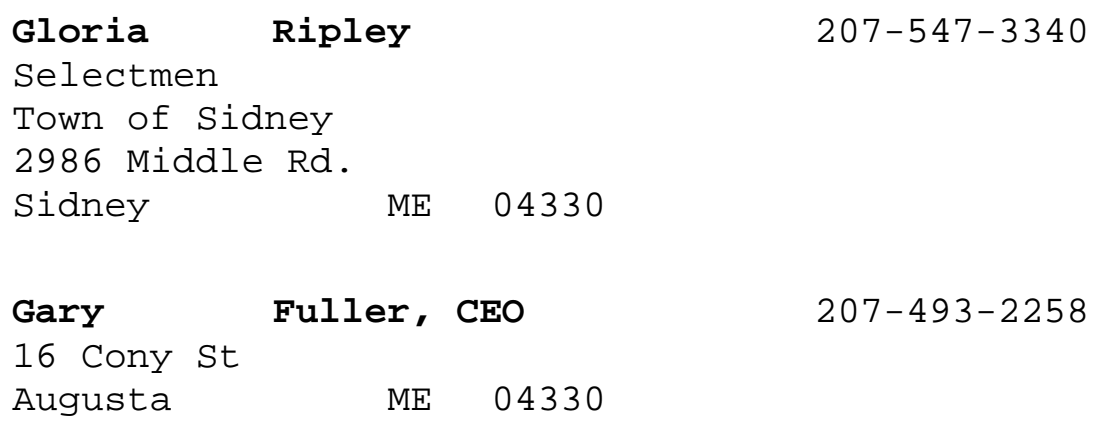

CID 230247 Community Profile

Current FIRM/FIS Map Date: 11/20/1998

Ordinance Date: 3/20/1999

All LOMCs: $\odot$

Best Available Data: ND

Mapping Status: ND

Mapping Needs: ND

ND, No Data; NSFHA, No Specific Flood Hazard Area 
COMMUNITY CONTACTS AND BEST AVAILABLE DATA: KENNEBEC COUNTY

\section{Unity TWP}

CID 230602

Community Profile

Map Type: NSFHA

Current FIRM/FIS Map Date:

Participating $=$ Yes LURC: Yes

Ordinance Date:

Total No. NFIP Policies=ND No. Claims Since 1978= ND

All LOMCs: $\odot$

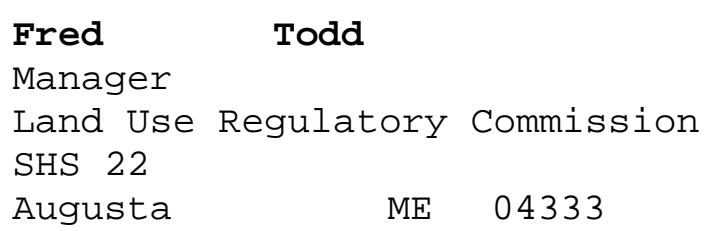

Augusta

ME $\odot 4333$

Charles

PO Box 22

Unity

Porter, Jr., CEO

$207-437-6325$

ME $\quad 04988$

Best Available Data: ND

Mapping Status: ND

Mapping Needs: ND

ND, No Data; NSFHA, No Specific Flood Hazard Area 
COMMUNITY CONTACTS AND BEST AVAILABLE DATA: KENNEBEC COUNTY

\section{Vassalboro, Town of}

Map Type: Unnumbered A-Zone

Participating $=$ No LURC: No

Total No. NFIP Policies=ND

No. Claims Since 1978= ND
CID 230248

Community Profile
Current FIRM/FIS Map Date: 2/7/1975

Ordinance Date: 6/15/2005

All LOMCs: 1

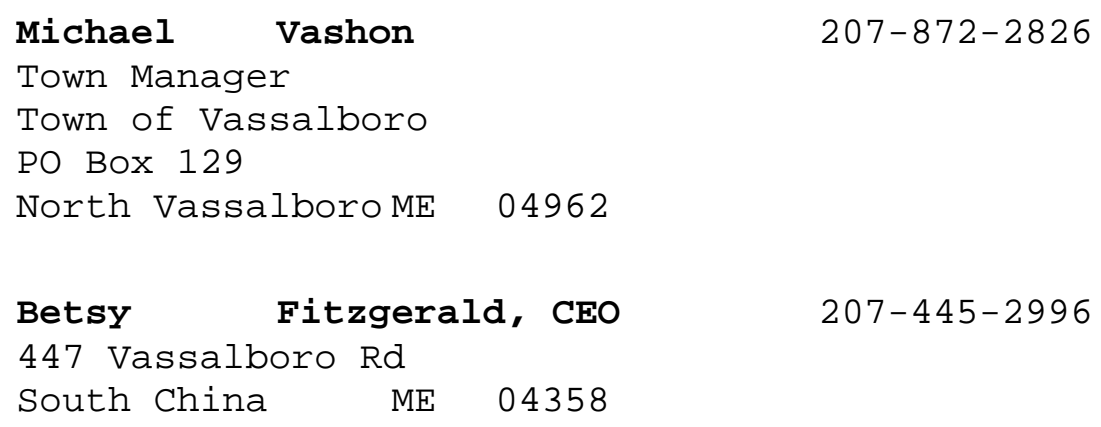

Best Available Data: ND

Mapping Status: D\&D will look at for XDS projects in '97/'98. (didn't happen )

Mapping Needs: Corporate boundary? Needs detailed study utilizing data from Augusta \& Sidney FIS

ND, No Data; NSFHA, No Specific Flood Hazard Area 
COMMUNITY CONTACTS AND BEST AVAILABLE DATA: KENNEBEC COUNTY

\section{Vienna, Town of}

Map Type: No Floodways

Participating=Yes LURC: No

Total No. NFIP Policies $=1$

No. Claims Since $1978=0$

$207-293-2087$

Randall Carl

Selectmen

Town of Vienna

PO Box 38

Vienna

ME $\quad 0436 \odot$

John Archard, CEO

RR 1 Box 615

Vienna

ME $\quad 04360$
CID 230249

Community Profile
Current FIRM/FIS Map Date: 11/20/1998

Ordinance Date: 3/6/1999

All LOMCs: $\odot$

Best Available Data: ND

Mapping Status: ND

Mapping Needs: ND

ND, No Data; NSFHA, No Specific Flood Hazard Area 
COMMUNITY CONTACTS AND BEST AVAILABLE DATA: KENNEBEC COUNTY

Waterville, City of

Map Type: Floodways

Participating=Yes LURC: No

Total No. NFIP Policies $=21 \quad$ No. Claims Since 1978= 7

Michael Roy

Administrator

City of Waterville

One Common St.

Waterville ME 04901

Garth Collins, CEO 207-873-7131

1 Common St

Waterville ME 04901

Best Available Data: ND

Mapping Status: ND

Mapping Needs: ND

$207-873-7131$
CID 230070 Community Profile

Current FIRM/FIS Map Date: 5/7/2001

Ordinance Date: 4/23/2001

All LOMCs: 1 
COMMUNITY CONTACTS AND BEST AVAILABLE DATA: KENNEBEC COUNTY

\section{Wayne, Town of}

Map Type: No Floodways

Current FIRM/FIS Map Date: 4/3/1989

Participating $=$ Yes LURC: No

Total No. NFIP Policies $=19$

No. Claims Since 1978= 25

$207-685-4983$

Gregory Davis

Town Manager

Town of Wayne

3 Lovejoy Pond Rd

Wayne

ME 04284

Kenneth Pratt, CEO

250 Patten Rd

Greene

ME $\quad 04236$
CID 230188

Community Profile
All LOMCs: 1

\section{Best Available Data: ND}

Mapping Status: ND

Mapping Needs: ND

ND, No Data; NSFHA, No Specific Flood Hazard Area 
COMMUNITY CONTACTS AND BEST AVAILABLE DATA: KENNEBEC COUNTY

West Gardiner, Town of

Map Type: Floodways

Participating=Yes LURC: No

Total No. NFIP Policies $=13$ No. Claims Since 1978= 5

Nancy O'Laughlin
Selectmen 207-724-3945
Town of West Gardiner
318 Spears Corner Rd.
West Gardiner ME 04345
Waldo Gilpatrick, CEO
68 Bog Hill Rd ME 04345
W. Gardiner

Best Available Data: ND

Mapping Status: ND

Mapping Needs: ND
CID $230250 \quad$ Community Profile

Current FIRM/FIS Map Date: 3/28/1980

Ordinance Date: 3/25/1995

All LOMCs: $\odot$ 
COMMUNITY CONTACTS AND BEST AVAILABLE DATA: KENNEBEC COUNTY

\section{Windsor, Town of}

Map Type: Unnumbered A-Zone

Participating $=$ Yes LURC: No

Total No. NFIP Policies $=4$

No. Claims Since $1978=0$

Current FIRM/FIS Map Date: 2/4/1987

Ordinance Date: 6/24/1987

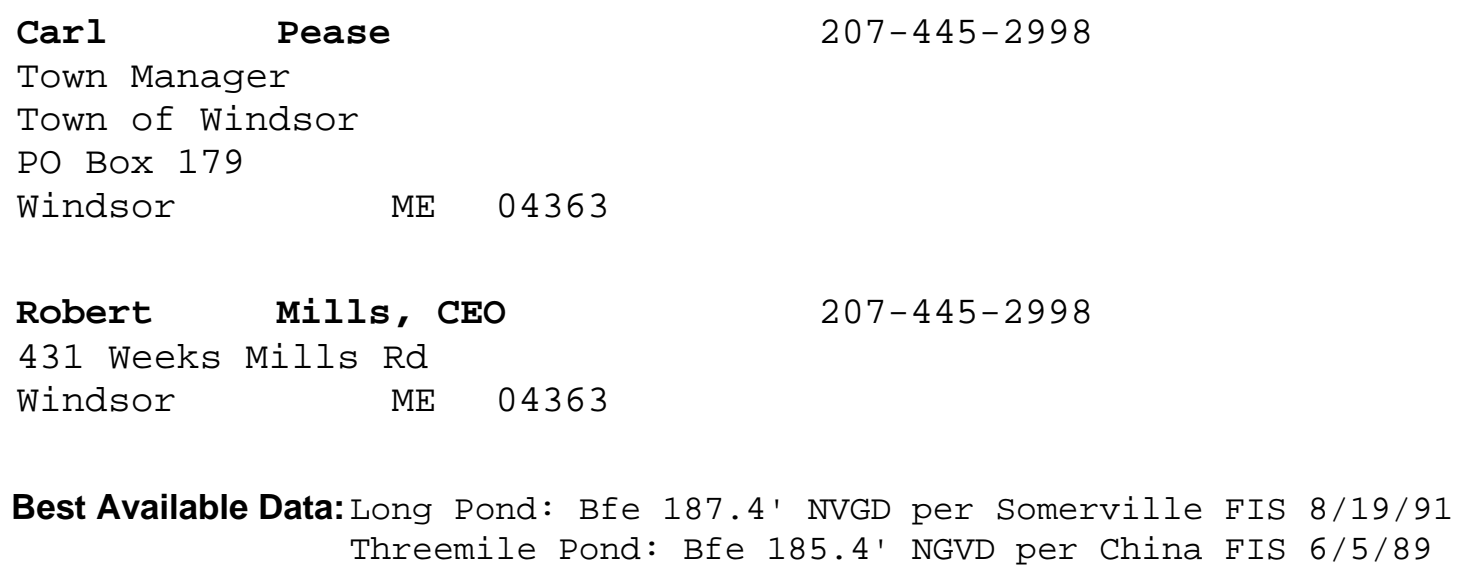

Mapping Status: ND

Mapping Needs: ND

ND, No Data; NSFHA, No Specific Flood Hazard Area 
COMMUNITY CONTACTS AND BEST AVAILABLE DATA: KENNEBEC COUNTY

Winslow, Town of

Map Type: Floodways

Participating=Yes LURC: No

Total No. NFIP Policies $=28$

No. Claims Since $1978=40$

Current FIRM/FIS Map Date: 5/7/2001

Ordinance Date: 6/11/2001

All LOMCs: 1

\author{
Edward Gagnon 207-872-2776 \\ Town Manager \\ Town of Winslow \\ 114 Benton Ave. \\ Winslow ME 04901 \\ Frank Stankevitz, CEO 207-872-2776 \\ 16 Benton Ave. \\ Winslow ME 04901 \\ Best Available Data: ND
}

Mapping Status: ND

Mapping Needs: ND

ND, No Data; NSFHA, No Specific Flood Hazard Area 
COMMUNITY CONTACTS AND BEST AVAILABLE DATA: KENNEBEC COUNTY

\section{Winthrop, Town of}

Map Type: No Floodways

Participating=Yes LURC: No

Total No. NFIP Policies=31 No. Claims Since 1978= 12

Cornell Knight

Town Manager

Town of Winthrop

17 Highland Ave.

Winthrop

ME $\quad 04364$

S. Elizabeth

P0 Box 418

Winthrop

ME $\quad 04364$
CID 230072

Community Profile
Current FIRM/FIS Map Date: 8/15/1980

Ordinance Date: 1/29/1997

All LOMCs: 9

Best Available Data: ND

Mapping Status: ND

Mapping Needs: ND

Young, CEO 207-377-2235

$207-377-7200$

\author{
Young, CEO 207-377-2235
}

Mapping Needs: ND

ND, No Data; NSFHA, No Specific Flood Hazard Area 
Appendix C: Community Scoping Interview Data: Kennebec County 
SCOPING INTERVIEW DATA FOR: Benton, Town of

CID: 230233

Council Govt:

Annual Town Meeting Date:

Town Govt: $\quad$ March

Community Representative Interviewed

Betsy Fitzgerald

Code Enforcement officer

Email: bfitz447@adelphia.net Tel: (207) 453-7191 Fax: (207) 453-4428

Floodplain Management Community Contact (if different from above)

Known problems with flood maps for your community

Do you have specific areas that don't flood ( $1 \%$ chance) but are currently in the floodplain? No

Do you have specific areas that flood ( $1 \%$ chance) but are not mapped in the floodplain?

Yes, Fowler Brook; 15-Mile Stream

Note any significant changes in hydraulic structures (bridges, culverts, dams)

Yes, new culvert on 15 Mile Stream

Do you have (or are you proposing) high-development areas where you need new or restudied flood elevations or improved map scale?

Yes, Fowler Brook and 15-Mile Stream

Community Resources

Do you have aerial photography (or plans for any) (flight date, scale, color/bw)?

No

Do you have any topographic data (or plans for collecting) (digital terrain, contour maps)? No

Do you have any data related to hydrologic/hydraulic studies (or plans for such studies)?

Yes. DOT?

Do you have dedicated GIS capabilities, and if so, provide contact information?

No

Notes

Study: Fowler Brook in detail; 15-Mile Stream in detail. Both high priority, but if push came to shove would pick Fowler as the higher priority. 


\section{SCOPING INTERVIEW DATA FOR: Chelsea, Town of}

\section{CID: 230234 Council Govt: Annual Town Meeting Date:}

Town Govt:

Community Representative Interviewed

Bob StPierre

CEO

Email:

Tel: (207) 582-4802 Fax: (207) 588-0025

Floodplain Management Community Contact (if different from above)

same

Known problems with flood maps for your community

Do you have specific areas that don't flood (1\% chance) but are currently in the floodplain?

None that the CEO has been made aware of.

Do you have specific areas that flood ( $1 \%$ chance) but are not mapped in the floodplain? No

Note any significant changes in hydraulic structures (bridges, culverts, dams)

None identified

Do you have (or are you proposing) high-development areas where you need new or restudied flood elevations or improved map scale?

No

\section{Community Resources}

Do you have aerial photography (or plans for any) (flight date, scale, color/bw)?

Yes. 5-13-72, 1"=400ft $(+$ or -$)$, black and white

Do you have any topographic data (or plans for collecting) (digital terrain, contour maps)? No

Do you have any data related to hydrologic/hydraulic studies (or plans for such studies)? No

Do you have dedicated GIS capabilities, and if so, provide contact information?

Yes. Enhanced 9-1-1 Maintenance Map Book (for Chelsea) from Maine state office of GIS

Notes 
SCOPING INTERVIEW DATA FOR: Gardiner, City of

CID: 230068

Council Govt:

Annual Town Meeting Date:

Town Govt: $\quad$ None - City Council

Community Representative Interviewed

Waldo Gilpatrick

Code Officer

Email: ceo@gardinermaine.com Tel: (207) 582-6892 Fax: (207) 582-6895

Floodplain Management Community Contact (if different from above)

Known problems with flood maps for your community

Do you have specific areas that don't flood (1\% chance) but are currently in the floodplain?

Yes, outer Marston Road

Do you have specific areas that flood ( $1 \%$ chance) but are not mapped in the floodplain? No

Note any significant changes in hydraulic structures (bridges, culverts, dams)

No

Do you have (or are you proposing) high-development areas where you need new or restudied flood elevations or improved map scale?

Yes, expanded super market and expanded elevated parking area

Community Resources

Do you have aerial photography (or plans for any) (flight date, scale, color/bw)?

No

Do you have any topographic data (or plans for collecting) (digital terrain, contour maps)? No

Do you have any data related to hydrologic/hydraulic studies (or plans for such studies)? No

Do you have dedicated GIS capabilities, and if so, provide contact information? No

Notes 
SCOPING INTERVIEW DATA FOR: Mount Vernon, Town of

CID: 230241

Council Govt: Annual Town Meeting Date:

Town Govt: ?

Community Representative Interviewed

Creston Gaither

Land Surveyor (not a town official)

Email: crestong@yahoo.com Tel: (207) 293-2909 Fax: (207) 293-9393

Floodplain Management Community Contact (if different from above)

Richard Marble, CEO (207) 293-2636

Known problems with flood maps for your community

Do you have specific areas that don't flood (1\% chance) but are currently in the floodplain?

Yes. French's Point, the peninsula in Flying Pond at the northwest corner of town (panel 5b), does not flood.

Do you have specific areas that flood ( $1 \%$ chance) but are not mapped in the floodplain? ?

Note any significant changes in hydraulic structures (bridges, culverts, dams)

?

Do you have (or are you proposing) high-development areas where you need new or restudied flood elevations or improved map scale?

?

Community Resources

Do you have aerial photography (or plans for any) (flight date, scale, color/bw)?

Don't know

Do you have any topographic data (or plans for collecting) (digital terrain, contour maps)? Don't know

Do you have any data related to hydrologic/hydraulic studies (or plans for such studies)? Don't know

Do you have dedicated GIS capabilities, and if so, provide contact information?

Don't know

Notes 


\section{SCOPING INTERVIEW DATA FOR: Oakland, TOWn of}

CID: 230242

Council Govt:

Annual Town Meeting Date:

Town Govt: 1 st week in May

Community Representative Interviewed

Bob Ellis

Code Enforcement Officer

Email: bellis@oaklandmaine.com Tel: (207) 465-2842 Fax: (207) 465-9118

Floodplain Management Community Contact (if different from above)

Bob Ellis

Known problems with flood maps for your community

Do you have specific areas that don't flood (1\% chance) but are currently in the floodplain? No

Do you have specific areas that flood ( $1 \%$ chance) but are not mapped in the floodplain? No

Note any significant changes in hydraulic structures (bridges, culverts, dams)

No

Do you have (or are you proposing) high-development areas where you need new or restudied flood elevations or improved map scale?

No

\section{Community Resources}

Do you have aerial photography (or plans for any) (flight date, scale, color/bw)?

Yes. Yearly Update; Black and white; entire town

Do you have any topographic data (or plans for collecting) (digital terrain, contour maps)? No

Do you have any data related to hydrologic/hydraulic studies (or plans for such studies)? No

Do you have dedicated GIS capabilities, and if so, provide contact information? No

Notes 
SCOPING INTERVIEW DATA FOR: Readfield, Town of

CID: 230245

Council Govt:

Annual Town Meeting Date:

Town Govt:

Community Representative Interviewed

Clif Buuck

Code Enforcement Officer

Email: readfield.ceo@adelphia.net Tel: (207) 685-3290 Fax: (207) 685-3420

Floodplain Management Community Contact (if different from above)

Known problems with flood maps for your community

Do you have specific areas that don't flood (1\% chance) but are currently in the floodplain?

Yes. Areas on Torsey Lake (affects Torsey Lake on 1b), also 6b (island).

Do you have specific areas that flood ( $1 \%$ chance) but are not mapped in the floodplain?

Yes. See panel 5b (road)

Note any significant changes in hydraulic structures (bridges, culverts, dams)

Yes. See panel 6b. All of Marancecook Lake is flooding now because dam in next town was rebuilt 15" too high. Expect to be resolved and cut by September 2006.

Do you have (or are you proposing) high-development areas where you need new or restudied flood elevations or improved map scale?

No

Community Resources

Do you have aerial photography (or plans for any) (flight date, scale, color/bw)?

Yes. 1998 Ice-storm photos, 2003 GIS photos.

Do you have any topographic data (or plans for collecting) (digital terrain, contour maps)? No

Do you have any data related to hydrologic/hydraulic studies (or plans for such studies)? No

Do you have dedicated GIS capabilities, and if so, provide contact information?

Being budgeted

Notes 


\section{SCOPING INTERVIEW DATA FOR: VasSalboro, Town of}

CID: 230248

Council Govt:

Annual Town Meeting Date:

Town Govt: June 2006

Community Representative Interviewed

Betsy Fitzgerald

Code Enforcement officer

Email: bfitz@vassalboro.net Tel: (207) 872-2826 Fax: (207) 872-5414

Floodplain Management Community Contact (if different from above)

Known problems with flood maps for your community

Do you have specific areas that don't flood (1\% chance) but are currently in the floodplain? No

Do you have specific areas that flood ( $1 \%$ chance) but are not mapped in the floodplain? No; rate map; Outlet stream?

Note any significant changes in hydraulic structures (bridges, culverts, dams)

Yes, outlet stream

Do you have (or are you proposing) high-development areas where you need new or restudied flood elevations or improved map scale?

Yes, Outlet Stream needs to be mapped

Community Resources

Do you have aerial photography (or plans for any) (flight date, scale, color/bw)? No

Do you have any topographic data (or plans for collecting) (digital terrain, contour maps)? No

Do you have any data related to hydrologic/hydraulic studies (or plans for such studies)? No

Do you have dedicated GIS capabilities, and if so, provide contact information?

No, but maybe in the future

Notes

See BAD summary sheet. Webber Pond, BFE exists?, some development on the outlet stream. 
SCOPING INTERVIEW DATA FOR: Vienna, TOWn of

CID: 230249

Council Govt:

Annual Town Meeting Date:

Town Govt: $\quad$ 1st Saturday in March

Community Representative Interviewed

Creston Gaither

Planning Board Secretary, Land Surveyor

Email: crestong@yahoo.com Tel: (207) 293-2909 Fax: (207) 293-9393

Floodplain Management Community Contact (if different from above)

same

Known problems with flood maps for your community

Do you have specific areas that don't flood (1\% chance) but are currently in the floodplain?

Yes. Based on planning board observations and discussions it appears that the eastern shore of Parker Pond does not flood.

Do you have specific areas that flood (1\% chance) but are not mapped in the floodplain? No

Note any significant changes in hydraulic structures (bridges, culverts, dams)

Yes. A substantially larger culvert has been placed at Stetson's Brook at Seaveys Corner Road (on panel 5c about 1200 feet south from the route 41 intersection).

Do you have (or are you proposing) high-development areas where you need new or restudied flood elevations or improved map scale?

No

\section{Community Resources}

Do you have aerial photography (or plans for any) (flight date, scale, color/bw)?

No, but these are readily available elsewhere.

Do you have any topographic data (or plans for collecting) (digital terrain, contour maps)? No, but these are readily available elsewhere.

Do you have any data related to hydrologic/hydraulic studies (or plans for such studies)? No

Do you have dedicated GIS capabilities, and if so, provide contact information? No

Notes 
SCOPING INTERVIEW DATA FOR: West Gardiner, Town of

CID: 230250

Council Govt:

Annual Town Meeting Date:

Town Govt: March

Community Representative Interviewed

Waldo Gilpatrick

Code officer

Email:

Tel: (207) 724-3945 Fax: (207) 724-6000

Floodplain Management Community Contact (if different from above)

Known problems with flood maps for your community

Do you have specific areas that don't flood (1\% chance) but are currently in the floodplain? No

Do you have specific areas that flood ( $1 \%$ chance) but are not mapped in the floodplain? No

Note any significant changes in hydraulic structures (bridges, culverts, dams)

No

Do you have (or are you proposing) high-development areas where you need new or restudied flood elevations or improved map scale?

Yes. Most all developed around lake and stream.

Community Resources

Do you have aerial photography (or plans for any) (flight date, scale, color/bw)? No

Do you have any topographic data (or plans for collecting) (digital terrain, contour maps)? No

Do you have any data related to hydrologic/hydraulic studies (or plans for such studies)? No

Do you have dedicated GIS capabilities, and if so, provide contact information? No

Notes 
SCOPING INTERVIEW DATA FOR: Winslow, TOWn of

CID: 230071

Council Govt:

Annual Town Meeting Date:

Town Govt: Monthly

Community Representative Interviewed

Frank Stankevitz

Code officer

Email: frank@winslowmaine.org Tel: (207) 872-2776 Fax: (207) 872-1999

Floodplain Management Community Contact (if different from above)

Known problems with flood maps for your community

Do you have specific areas that don't flood (1\% chance) but are currently in the floodplain?

Yes, Pattee Pond

Do you have specific areas that flood ( $1 \%$ chance) but are not mapped in the floodplain? No

Note any significant changes in hydraulic structures (bridges, culverts, dams)

Yes. FPLE to remove the Halifax dam (Application in process); 3rd Bridge on

Kennebec River.

Do you have (or are you proposing) high-development areas where you need new or restudied flood elevations or improved map scale?

No

Community Resources

Do you have aerial photography (or plans for any) (flight date, scale, color/bw)?

Yes, Town flown in 1993

Do you have any topographic data (or plans for collecting) (digital terrain, contour maps)? No

Do you have any data related to hydrologic/hydraulic studies (or plans for such studies)? Yes, FPL being required to restudy for Halifax Dam

Do you have dedicated GIS capabilities, and if so, provide contact information? Yes

Notes 
Appendix D: Existing MNUSS Data Entries: Kennebec County 


\section{BENTON, TOWN OF}

MNUSS NeedID 100000000010194

Sebasticook River

Need Desc: Changes to hydraulic analysis
CID 230233 MNUSS Summary

Date of Need: 8/4/1997

Panel: $2302330004 \mathrm{~B}$

Length: $\odot .9 \mathrm{mi}$

Anticipated BFE Change: Increased By Greater Than 5 feet

Location of Floodplain:

Need Notes: Have added a dam on Sebasticook River.

SPO Comments: valid

MNUSS NeedID 100000000010194

Date of Need: 8/4/1997

Sebasticook River

Need Desc: Changes to hydraulic analysis

Panel: $2302330004 \mathrm{~B}$

Length: $0.9 \mathrm{mi}$

Anticipated BFE Change: Increased By Greater Than 5 feet

Location of Floodplain:

Need Notes: Have added a dam on Sebasticook River.

SPO Comments: valid 
EXISTING MNUSS ENTRIES FOR KENNEBEC COUNTY

\section{BENTON, TOWN OF}

MNUSS NeedID 100000000010194

Sebasticook River

Need Desc: Changes to hydraulic analysis
CID 230233 MNUSS Summary

Date of Need: 8/4/1997

Panel: $2302330004 \mathrm{~B}$

Length: $0.9 \mathrm{mi}$

Anticipated BFE Change: Increased By Greater Than 5 feet

Location of Floodplain:

Need Notes: Have added a dam on Sebasticook River.

SPO Comments: valid 
EXISTING MNUSS ENTRIES FOR KENNEBEC COUNTY

\section{CHINA, TOWN OF}

MNUSS NeedID 100000000010240

Need Desc: Add LOMCs (per panel)

Anticipated BFE Change: Not Applicable

Location of Floodplain:

Need Notes:

SPO Comments: DFIRM will address

MNUSS NeedID 100000000010240

Need Desc: Add LOMCs (per panel)

Anticipated BFE Change: Not Applicable

Location of Floodplain:

Need Notes:

SPO Comments: DFIRM will address
CID 230235 MNUSS Summary

Date of Need: 11/11/1997

Panel: 2302350005B

Length: $\odot \quad$ mi
Date of Need: 11/11/1997

Panel: $2302350010 \mathrm{~B}$

Length: $\odot \quad$ mi 
EXISTING MNUSS ENTRIES FOR KENNEBEC COUNTY

\section{CHINA, TOWN OF}

MNUSS NeedID 100000000010373

Need Desc: Annexation and corporate limits (per panel)

Anticipated BFE Change: Not Applicable

Location of Floodplain:

Need Notes:

SPO Comments: DFIRM will address

MNUSS NeedID 100000000010373

Need Desc: Annexation and corporate limits (per panel)

Anticipated BFE Change: Not Applicable

Location of Floodplain:

Need Notes:

SPO Comments: DFIRM will address
CID 230235 MNUSS Summary

Date of Need: 6/8/1999

Panel: 2302350005B

Length: $\odot \quad$ mi
Date of Need: 6/8/1999

Panel: 2302350010B

Length: $\odot \quad$ mi 
EXISTING MNUSS ENTRIES FOR KENNEBEC COUNTY

\section{CHINA, TOWN OF}

MNUSS NeedID 100000000010373

Need Desc: Annexation and corporate limits (per panel)

Anticipated BFE Change: Not Applicable

Location of Floodplain:

Need Notes:

SPO Comments: DFIRM will address

MNUSS NeedID 100000000025857

Need Desc: Add an ERM
CID 230235 MNUSS Summary

Date of Need: 6/8/1999

Panel: 2302350015B

Length: $\odot \quad$ mi
Date of Need: $8 / 29 / 2001$

Panel: $2300690004 \mathrm{C}$

Length: $\odot \quad$ mi

Anticipated BFE Change: Not Applicable

Location of Floodplain:

Need Notes: The elevation for RM 3 may or may not be correct. It is published at $60.91 \mathrm{NGVD}$, but $\mathrm{Mr}$. Laughlin claims it is really 68.91 NGVD.

SPO Comments: valid 
EXISTING MNUSS ENTRIES FOR KENNEBEC COUNTY

\section{MANCHESTER, TOWN OF}

MNUSS NeedID 100000000010160

Need Desc: Add streets to panel

Anticipated BFE Change: Not Applicable

Location of Floodplain:

Need Notes:

SPO Comments: DFIRM will address

MNUSS NeedID 100000000010160

Need Desc: Add streets to panel

Anticipated BFE Change: Not Applicable

Location of Floodplain:

Need Notes:

SPO Comments: DFIRM will address
CID 230239 MNUSS Summary

Date of Need: 8/4/1997

Panel: 2302390004B

Length: $\odot \quad$ mi
Date of Need: 8/4/1997

Panel: 2302390010B

Length: $\odot \quad$ mi 
EXISTING MNUSS ENTRIES FOR KENNEBEC COUNTY

\section{MANCHESTER, TOWN OF}

MNUSS NeedID 100000000010160

Need Desc: Add streets to panel

Anticipated BFE Change: Not Applicable

Location of Floodplain:

Need Notes:

SPO Comments: DFIRM will address

MNUSS NeedID 100000000010160

Need Desc: Add streets to panel

Anticipated BFE Change: Not Applicable

Location of Floodplain:

Need Notes:

SPO Comments: DFIRM will address
CID 230239 MNUSS Summary

Date of Need: 8/4/1997

Panel: 2302390009B

Length: $\odot \quad$ mi
Date of Need: 8/4/1997

Panel: 2302390008B

Length: $\odot \quad \mathrm{mi}$ 
EXISTING MNUSS ENTRIES FOR KENNEBEC COUNTY

\section{MANCHESTER, TOWN OF}

MNUSS NeedID 100000000010160

Need Desc: Add streets to panel

Anticipated BFE Change: Not Applicable

Location of Floodplain:

Need Notes:

SPO Comments: DFIRM will address

MNUSS NeedID 100000000010160

Need Desc: Add streets to panel

Anticipated BFE Change: Not Applicable

Location of Floodplain:

Need Notes:

SPO Comments: DFIRM will address
CID 230239 MNUSS Summary

Date of Need: 8/4/1997

Panel: 2302390007B

Length: $\odot \quad \mathrm{mi}$
Date of Need: 8/4/1997

Panel: 2302390005B

Length: $\odot \quad$ mi 
EXISTING MNUSS ENTRIES FOR KENNEBEC COUNTY

\section{MANCHESTER, TOWN OF}

MNUSS NeedID 100000000010160

Need Desc: Add streets to panel

Anticipated BFE Change: Not Applicable

Location of Floodplain:

Need Notes:

SPO Comments: DFIRM will address

MNUSS NeedID 100000000010160

Need Desc: Add streets to panel

Anticipated BFE Change: Not Applicable

Location of Floodplain:

Need Notes:

SPO Comments: DFIRM will address
CID 230239 MNUSS Summary

Date of Need: 8/4/1997

Panel: 2302390011B

Length: $\odot \quad$ mi
Date of Need: 8/4/1997

Panel: 2302390003B

Length: $\odot \quad \mathrm{mi}$ 
EXISTING MNUSS ENTRIES FOR KENNEBEC COUNTY

\section{MANCHESTER, TOWN OF}

MNUSS NeedID 100000000010160

Need Desc: Add streets to panel

Anticipated BFE Change: Not Applicable

Location of Floodplain:

Need Notes:

SPO Comments: DFIRM will address

MNUSS NeedID 100000000010160

Need Desc: Add streets to panel

Anticipated BFE Change: Not Applicable

Location of Floodplain:

Need Notes:

SPO Comments: DFIRM will address
CID 230239 MNUSS Summary

Date of Need: 8/4/1997

Panel: 2302390001B

Length: $\odot \quad \mathrm{mi}$
Date of Need: 8/4/1997

Panel: 2302390006B

Length: $\odot \quad$ mi 


\section{MONMOUTH, TOWN OF}

MNUSS NeedID 100000000010292

NUMEROUS ZONE A's

Need Desc: Changes to hydrologic conditions
CID 230240 MNUSS Summary

Date of Need: 12/15/1997

Panel: $2302400010 \mathrm{~A}$

Length: $19.6 \mathrm{mi}$

Anticipated BFE Change: Increased By Greater Than 5 feet

Location of Floodplain:

Need Notes: COMMUNITY REUESTS A RESTUDY TO INCLUDE FLOODWAYS

SPO Comments: any chg due to dam failure?

MNUSS NeedID 100000000010292

Date of Need: 12/15/1997

NUMEROUS ZONE A's

Panel: $2302400015 \mathrm{~A}$

Need Desc: Changes to hydrologic conditions

Length: $19.6 \mathrm{mi}$

Anticipated BFE Change: Increased By Greater Than 5 feet

Location of Floodplain:

Need Notes: COMMUNITY REUESTS A RESTUDY TO INCLUDE FLOODWAYS

SPO Comments: unsure 


\section{MONMOUTH, TOWN OF}

MNUSS NeedID 100000000010292

NUMEROUS ZONE A's

Need Desc: Changes to hydrologic conditions
CID 230240 MNUSS Summary

Date of Need: 12/15/1997

Panel: $2302400015 \mathrm{~A}$

Length: $19.6 \mathrm{mi}$

Anticipated BFE Change: Increased By Greater Than 5 feet

Location of Floodplain:

Need Notes: COMMUNITY REUESTS A RESTUDY TO INCLUDE FLOODWAYS

SPO Comments: unsure

MNUSS NeedID 100000000010292

Date of Need: 12/15/1997

NUMEROUS ZONE A's

Panel: $2302400010 \mathrm{~A}$

Need Desc: Changes to hydrologic conditions

Length: $19.6 \mathrm{mi}$

Anticipated BFE Change: Increased By Greater Than 5 feet

Location of Floodplain:

Need Notes: COMMUNITY REUESTS A RESTUDY TO INCLUDE FLOODWAYS

SPO Comments: unsure 


\section{MONMOUTH, TOWN OF}

MNUSS NeedID 100000000010292

NUMEROUS ZONE A's

Need Desc: Changes to hydrologic conditions
CID 230240 MNUSS Summary

Date of Need: 12/15/1997

Panel: $2302400005 \mathrm{~A}$

Length: $19.6 \mathrm{mi}$

Anticipated BFE Change: Increased By Greater Than 5 feet

Location of Floodplain:

Need Notes: COMMUNITY REUESTS A RESTUDY TO INCLUDE FLOODWAYS

SPO Comments: unsure

MNUSS NeedID 100000000010292

Date of Need: 12/15/1997

NUMEROUS ZONE A's

Panel: $2302400005 \mathrm{~A}$

Need Desc: Changes to hydrologic conditions

Length: $19.6 \mathrm{mi}$

Anticipated BFE Change: Increased By Greater Than 5 feet

Location of Floodplain:

Need Notes: COMMUNITY REUESTS A RESTUDY TO INCLUDE FLOODWAYS

SPO Comments: unsure 


\section{MONMOUTH, TOWN OF}

MNUSS NeedID 100000000010291

Need Desc: Add LOMCs (per panel)

Anticipated BFE Change: Not Applicable

Location of Floodplain:

Need Notes:

SPO Comments: DFIRM will address

MNUSS NeedID 100000000010291

Need Desc: Add LOMCs (per panel)

Anticipated BFE Change: Not Applicable

Location of Floodplain:

Need Notes:

SPO Comments: DFIRM will address
CID 230240 MNUSS Summary

Date of Need: $12 / 15 / 1997$

Panel: $2302400015 \mathrm{~A}$

Length: $\odot \quad$ mi
Date of Need: 12/15/1997

Panel: $2302400005 \mathrm{~A}$

Length: $\odot \quad$ mi 
EXISTING MNUSS ENTRIES FOR KENNEBEC COUNTY

MONMOUTH, TOWN OF

MNUSS NeedID 100000000010291

Need Desc: Add LOMCs (per panel)

Anticipated BFE Change: Not Applicable

Location of Floodplain:

Need Notes:

SPO Comments: DFIRM will address
CID 230240 MNUSS Summary

Date of Need: 12/15/1997

Panel: 2302400010A

Length: $\odot \quad$ mi 


\section{MT. VERNON, TOWN OF}

MNUSS NeedID 100000000010331

\section{ALL A-ZONES}

Need Desc: Changes to hydraulic analysis
CID 230241 MNUSS Summary

Date of Need: $12 / 22 / 1997$

Panel: $2302410005 \mathrm{~B}$

Length: 17 mi

Anticipated BFE Change: Increased By Greater Than 5 feet

Location of Floodplain:

Need Notes: TOWN WOULD LIKE TO HAVE BFE'S DETERMINED FOR ALL ZONE A FLOODING SOURCES.

SPO Comments: new FIS in 2001

MNUSS NeedID 100000000010331

ALL A-ZONES

Need Desc: Changes to hydraulic analysis
Date of Need: 12/22/1997

Panel: 2302410005B

Length: 17 mi

Anticipated BFE Change: Increased By Greater Than 5 feet

Location of Floodplain:

Need Notes: TOWN WOULD LIKE TO HAVE BFE'S DETERMINED FOR ALL ZONE A FLOODING SOURCES.

SPO Comments: new FIS in 2001 


\section{MT. VERNON, TOWN OF}

MNUSS NeedID 100000000010331

\section{ALL A-ZONES}

Need Desc: Changes to hydraulic analysis
CID 230241 MNUSS Summary

Date of Need: $12 / 22 / 1997$

Panel: $2302410025 B$

Length: 17 mi

Anticipated BFE Change: Increased By Greater Than 5 feet

Location of Floodplain:

Need Notes: TOWN WOULD LIKE TO HAVE BFE'S DETERMINED FOR ALL ZONE A FLOODING SOURCES.

SPO Comments: new FIS in 2001

MNUSS NeedID 100000000010331

ALL A-ZONES

Need Desc: Changes to hydraulic analysis
Date of Need: 12/22/1997

Panel: 2302410025B

Length: 17 mi

Anticipated BFE Change: Increased By Greater Than 5 feet

Location of Floodplain:

Need Notes: TOWN WOULD LIKE TO HAVE BFE'S DETERMINED FOR ALL ZONE A FLOODING SOURCES.

SPO Comments: new FIS in 2001 
EXISTING MNUSS ENTRIES FOR KENNEBEC COUNTY

\section{READFIELD, TOWN OF}

MNUSS NeedID 100000000010220

Need Desc: Add streets to panel
CID 230245 MNUSS Summary

Date of Need: $11 / 6 / 1997$

Panel: 2302450006B

Length: $\odot \quad$ mi

Anticipated BFE Change: Not Applicable

Location of Floodplain:

Need Notes: MARANACOOK MISLABELED IN THE MIDDLE OF THE PANEL

SPO Comments: DFIRM will address

MNUSS NeedID 100000000010220

Date of Need: $11 / 6 / 1997$

Panel: 2302450006B

Need Desc: Add streets to panel

Length: $\odot \quad \mathrm{mi}$

Anticipated BFE Change: Not Applicable

Location of Floodplain:

Need Notes: MARANACOOK MISLABELED IN THE MIDDLE OF THE PANEL

SPO Comments: DFIRM will address 
EXISTING MNUSS ENTRIES FOR KENNEBEC COUNTY

\section{READFIELD, TOWN OF}

MNUSS NeedID 100000000010220

Need Desc: Add streets to panel
CID 230245 MNUSS Summary

Date of Need: $11 / 6 / 1997$

Panel: 2302450006B

Length: $\odot \quad$ mi

Anticipated BFE Change: Not Applicable

Location of Floodplain:

Need Notes: MARANACOOK MISLABELED IN THE MIDDLE OF THE PANEL

SPO Comments: DFIRM will address

MNUSS NeedID 100000000025734

Need Desc: Align map panels
Date of Need: $8 / 23 / 2001$

Panel: 2302460005B

Length: $\odot \quad$ mi

Anticipated BFE Change: Not Applicable

Location of Floodplain:

Need Notes: Zone A mismatch with Mount Vernon near Belgrade Road.

SPO Comments: DFIRM will address 
EXISTING MNUSS ENTRIES FOR KENNEBEC COUNTY

\section{VIENNA, TOWN OF}

MNUSS NeedID 100000000010370

\section{PARKER POND}

Need Desc: Changes to floodplain width
CID 230249 MNUSS Summary

Date of Need: 3/18/1999

Panel: $2302490010 \mathrm{C}$

Length: $1.57 \mathrm{mi}$

Anticipated BFE Change: Increased By Greater Than 5 feet

Location of Floodplain:

Need Notes:

SPO Comments: ? 
EXISTING MNUSS ENTRIES FOR KENNEBEC COUNTY

\section{WATERVILLE, CITY OF}

MNUSS NeedID 100000000010207

KENNEBEC RIVER

Need Desc: Changes to hydrologic conditions
CID 230070 MNUSS Summary

Date of Need: $10 / 6 / 1997$

Panel: $2300700003 \mathrm{~B}$

Length: $6.8 \mathrm{mi}$

Anticipated BFE Change: Increased By Greater Than 5 feet

Location of Floodplain:

Need Notes:

SPO Comments: new FIS in 2001

MNUSS NeedID 100000000010207

Date of Need: $10 / 6 / 1997$

KENNEBEC RIVER

Need Desc: Changes to hydrologic conditions

Panel: $2300700005 \mathrm{~B}$

Length: $6.8 \mathrm{mi}$

Anticipated BFE Change: Increased By Greater Than 5 feet

Location of Floodplain:

Need Notes:

SPO Comments: new FIS in 2001 
EXISTING MNUSS ENTRIES FOR KENNEBEC COUNTY

\section{WATERVILLE, CITY OF}

MNUSS NeedID 100000000010207

KENNEBEC RIVER

Need Desc: Changes to hydrologic conditions
CID 230070 MNUSS Summary

Date of Need: $10 / 6 / 1997$

Panel: $2300700006 \mathrm{~B}$

Length: $6.8 \mathrm{mi}$

Anticipated BFE Change: Increased By Greater Than 5 feet

Location of Floodplain:

Need Notes:

SPO Comments: new FIS in 2001

MNUSS NeedID 100000000010207

Date of Need: $10 / 6 / 1997$

KENNEBEC RIVER

Need Desc: Changes to hydrologic conditions

Panel: $2300700008 \mathrm{~B}$

Length: $6.8 \mathrm{mi}$

Anticipated BFE Change: Increased By Greater Than 5 feet

Location of Floodplain:

Need Notes:

SPO Comments: new FIS in 2001 
EXISTING MNUSS ENTRIES FOR KENNEBEC COUNTY

\section{WATERVILLE, CITY OF}

MNUSS NeedID 100000000010206

Need Desc: Add LOMCs (per panel)

Anticipated BFE Change: Not Applicable

Location of Floodplain:

Need Notes:

SPO Comments: new FIS in 2001
CID 230070 MNUSS Summary

Date of Need: $10 / 6 / 1997$

Panel: $2300700005 \mathrm{~B}$

Length: $\odot \quad$ mi 


\section{WEST GARDINER, TOWN OF}

MNUSS NeedID 100000000010212

Need Desc: Align map panels

Anticipated BFE Change: Not Applicable

Location of Floodplain:

Need Notes: UPDATE TO MAP INITIATIVES FORMAT

SPO Comments: DFIRM will address

MNUSS NeedID 100000000010212

Need Desc: Align map panels

Anticipated BFE Change: Not Applicable

Location of Floodplain:

Need Notes: UPDATE TO MAP INITIATIVES FORMAT

SPO Comments: DFIRM will address
CID 230250 MNUSS Summary

Date of Need: $11 / 6 / 1997$

Panel: 2302500009B

Length: $\odot \quad$ mi
Date of Need: $11 / 6 / 1997$

Panel: 2302500007B

Length: $\odot \quad$ mi 


\section{WEST GARDINER, TOWN OF}

MNUSS NeedID 100000000010212

Need Desc: Align map panels

Anticipated BFE Change: Not Applicable

Location of Floodplain:

Need Notes: UPDATE TO MAP INITIATIVES FORMAT

SPO Comments: DFIRM will address

MNUSS NeedID 100000000010212

Need Desc: Align map panels

Anticipated BFE Change: Not Applicable

Location of Floodplain:

Need Notes: UPDATE TO MAP INITIATIVES FORMAT

SPO Comments: DFIRM will address
CID 230250 MNUSS Summary

Date of Need: $11 / 6 / 1997$

Panel: 2302500007B

Length: $\odot \quad$ mi
Date of Need: $11 / 6 / 1997$

Panel: 2302500007B

Length: $\odot \quad$ mi 


\section{WEST GARDINER, TOWN OF}

MNUSS NeedID 100000000010212

Need Desc: Align map panels

Anticipated BFE Change: Not Applicable

Location of Floodplain:

Need Notes: UPDATE TO MAP INITIATIVES FORMAT

SPO Comments: DFIRM will address

MNUSS NeedID 100000000010212

Need Desc: Align map panels

Anticipated BFE Change: Not Applicable

Location of Floodplain:

Need Notes: UPDATE TO MAP INITIATIVES FORMAT

SPO Comments: DFIRM will address
CID 230250 MNUSS Summary

Date of Need: $11 / 6 / 1997$

Panel: 2302500008B

Length: $\odot \quad$ mi
Date of Need: 11/6/1997

Panel: 2302500008B

Length: $\odot \quad$ mi 


\section{WEST GARDINER, TOWN OF}

MNUSS NeedID 100000000010212

Need Desc: Align map panels

Anticipated BFE Change: Not Applicable

Location of Floodplain:

Need Notes: UPDATE TO MAP INITIATIVES FORMAT

SPO Comments: DFIRM will address

MNUSS NeedID 100000000010212

Need Desc: Align map panels

Anticipated BFE Change: Not Applicable

Location of Floodplain:

Need Notes: UPDATE TO MAP INITIATIVES FORMAT

SPO Comments: DFIRM will address
CID 230250 MNUSS Summary

Date of Need: $11 / 6 / 1997$

Panel: 2302500008B

Length: $\odot \quad$ mi
Date of Need: $11 / 6 / 1997$

Panel: 2302500006B

Length: $\odot \quad$ mi 


\section{WEST GARDINER, TOWN OF}

MNUSS NeedID 100000000010212

Need Desc: Align map panels

Anticipated BFE Change: Not Applicable

Location of Floodplain:

Need Notes: UPDATE TO MAP INITIATIVES FORMAT

SPO Comments: DFIRM will address

MNUSS NeedID 100000000010212

Need Desc: Align map panels

Anticipated BFE Change: Not Applicable

Location of Floodplain:

Need Notes: UPDATE TO MAP INITIATIVES FORMAT

SPO Comments: DFIRM will address
CID 230250 MNUSS Summary

Date of Need: $11 / 6 / 1997$

Panel: 2302500009B

Length: $\odot \quad$ mi
Date of Need: $11 / 6 / 1997$

Panel: 2302500005B

Length: $\odot \quad$ mi 


\section{WEST GARDINER, TOWN OF}

MNUSS NeedID 100000000010212

Need Desc: Align map panels

Anticipated BFE Change: Not Applicable

Location of Floodplain:

Need Notes: UPDATE TO MAP INITIATIVES FORMAT

SPO Comments: DFIRM will address

MNUSS NeedID 100000000010212

Need Desc: Align map panels

Anticipated BFE Change: Not Applicable

Location of Floodplain:

Need Notes: UPDATE TO MAP INITIATIVES FORMAT

SPO Comments: DFIRM will address
CID 230250 MNUSS Summary

Date of Need: $11 / 6 / 1997$

Panel: $2302500010 \mathrm{~B}$

Length: $\odot \quad$ mi
Date of Need: 11/6/1997

Panel: $2302500010 \mathrm{~B}$

Length: $\odot \quad$ mi 


\section{WEST GARDINER, TOWN OF}

MNUSS NeedID 100000000010212

Need Desc: Align map panels

Anticipated BFE Change: Not Applicable

Location of Floodplain:

Need Notes: UPDATE TO MAP INITIATIVES FORMAT

SPO Comments: DFIRM will address

MNUSS NeedID 100000000010213

Need Desc: Annexation and corporate limits (per panel)

Anticipated BFE Change: Not Applicable

Location of Floodplain:

Need Notes:

SPO Comments: DFIRM will address
CID 230250 MNUSS Summary

Date of Need: $11 / 6 / 1997$

Panel: $2302500010 \mathrm{~B}$

Length: $\odot \quad$ mi
Date of Need: 11/6/1997

Panel: 2302500002B

Length: $\odot \quad$ mi 


\section{WEST GARDINER, TOWN OF}

MNUSS NeedID 100000000010212

Need Desc: Align map panels

Anticipated BFE Change: Not Applicable

Location of Floodplain:

Need Notes: UPDATE TO MAP INITIATIVES FORMAT

SPO Comments: DFIRM will address

MNUSS NeedID 100000000010212

Need Desc: Align map panels

Anticipated BFE Change: Not Applicable

Location of Floodplain:

Need Notes: UPDATE TO MAP INITIATIVES FORMAT

SPO Comments: DFIRM will address
CID 230250 MNUSS Summary

Date of Need: $11 / 6 / 1997$

Panel: 2302500009B

Length: $\odot \quad$ mi
Date of Need: 11/6/1997

Panel: 2302500006B

Length: $\odot \quad$ mi 


\section{WEST GARDINER, TOWN OF}

MNUSS NeedID 100000000010212

Need Desc: Align map panels

Anticipated BFE Change: Not Applicable

Location of Floodplain:

Need Notes: UPDATE TO MAP INITIATIVES FORMAT

SPO Comments: DFIRM will address

MNUSS NeedID 100000000010212

Need Desc: Align map panels

Anticipated BFE Change: Not Applicable

Location of Floodplain:

Need Notes: UPDATE TO MAP INITIATIVES FORMAT

SPO Comments: DFIRM will address
CID 230250 MNUSS Summary

Date of Need: $11 / 6 / 1997$

Panel: 2302500005B

Length: $\odot \quad$ mi
Date of Need: 11/6/1997

Panel: 2302500005B

Length: $\odot \quad$ mi 


\section{WEST GARDINER, TOWN OF}

MNUSS NeedID 100000000010212

Need Desc: Align map panels

Anticipated BFE Change: Not Applicable

Location of Floodplain:

Need Notes: UPDATE TO MAP INITIATIVES FORMAT

SPO Comments: DFIRM will address

MNUSS NeedID 100000000010212

Need Desc: Align map panels

Anticipated BFE Change: Not Applicable

Location of Floodplain:

Need Notes: UPDATE TO MAP INITIATIVES FORMAT

SPO Comments: DFIRM will address
CID 230250 MNUSS Summary

Date of Need: $11 / 6 / 1997$

Panel: 2302500003B

Length: $\odot \quad$ mi
Date of Need: 11/6/1997

Panel: 2302500003B

Length: $\odot \quad$ mi 


\section{WEST GARDINER, TOWN OF}

MNUSS NeedID 100000000010212

Need Desc: Align map panels

Anticipated BFE Change: Not Applicable

Location of Floodplain:

Need Notes: UPDATE TO MAP INITIATIVES FORMAT

SPO Comments: DFIRM will address

MNUSS NeedID 100000000010212

Need Desc: Align map panels

Anticipated BFE Change: Not Applicable

Location of Floodplain:

Need Notes: UPDATE TO MAP INITIATIVES FORMAT

SPO Comments: DFIRM will address
CID 230250 MNUSS Summary

Date of Need: $11 / 6 / 1997$

Panel: 2302500003B

Length: $\odot \quad$ mi
Date of Need: 11/6/1997

Panel: $2302500002 B$

Length: $\odot \quad$ mi 


\section{WEST GARDINER, TOWN OF}

MNUSS NeedID 100000000010212

Need Desc: Align map panels

Anticipated BFE Change: Not Applicable

Location of Floodplain:

Need Notes: UPDATE TO MAP INITIATIVES FORMAT

SPO Comments: DFIRM will address

MNUSS NeedID 100000000010212

Need Desc: Align map panels

Anticipated BFE Change: Not Applicable

Location of Floodplain:

Need Notes: UPDATE TO MAP INITIATIVES FORMAT

SPO Comments: DFIRM will address
CID 230250 MNUSS Summary

Date of Need: $11 / 6 / 1997$

Panel: $2302500002 \mathrm{~B}$

Length: $\odot \quad$ mi
Date of Need: 11/6/1997

Panel: $2302500002 B$

Length: $\odot \quad$ mi 


\section{WEST GARDINER, TOWN OF}

MNUSS NeedID 100000000010212

Need Desc: Align map panels

Anticipated BFE Change: Not Applicable

Location of Floodplain:

Need Notes: UPDATE TO MAP INITIATIVES FORMAT

SPO Comments: DFIRM will address

MNUSS NeedID 100000000010212

Need Desc: Align map panels

Anticipated BFE Change: Not Applicable

Location of Floodplain:

Need Notes: UPDATE TO MAP INITIATIVES FORMAT

SPO Comments: DFIRM will address
CID 230250 MNUSS Summary

Date of Need: $11 / 6 / 1997$

Panel: 2302500001B

Length: $\odot \quad$ mi
Date of Need: 11/6/1997

Panel: 2302500001B

Length: $\odot \quad$ mi 


\section{WEST GARDINER, TOWN OF}

MNUSS NeedID 100000000010212

Need Desc: Align map panels

Anticipated BFE Change: Not Applicable

Location of Floodplain:

Need Notes: UPDATE TO MAP INITIATIVES FORMAT

SPO Comments: DFIRM will address

MNUSS NeedID 100000000010211

Need Desc: Add streets to panel

Anticipated BFE Change: Not Applicable

Location of Floodplain:

Need Notes:

SPO Comments: DFIRM will address
CID 230250 MNUSS Summary

Date of Need: $11 / 6 / 1997$

Panel: 2302500001B

Length: $\odot \quad \mathrm{mi}$
Date of Need: 11/6/1997

Panel: 2302500005B

Length: $\odot \quad$ mi 


\section{WEST GARDINER, TOWN OF}

MNUSS NeedID 100000000010211

Need Desc: Add streets to panel

Anticipated BFE Change: Not Applicable

Location of Floodplain:

Need Notes:

SPO Comments: DFIRM will address

MNUSS NeedID 100000000010212

Need Desc: Align map panels

Anticipated BFE Change: Not Applicable

Location of Floodplain:

Need Notes: UPDATE TO MAP INITIATIVES FORMAT

SPO Comments: DFIRM will address
CID 230250 MNUSS Summary

Date of Need: $11 / 6 / 1997$

Panel: $2302500002 \mathrm{~B}$

Length: $\odot \quad$ mi
Date of Need: 11/6/1997

Panel: 2302500006B

Length: $\odot \quad$ mi 
Appendix E: Attachments 


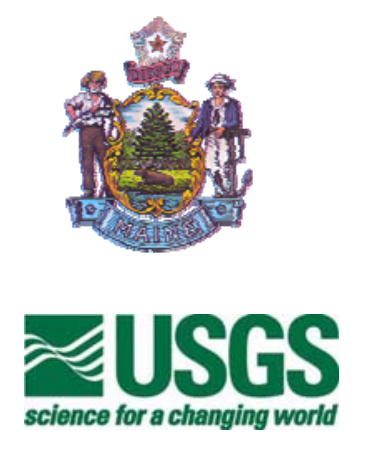

Bruce Keller, City Planner

City of Augusta

16 Cony Street

Augusta, Maine 04330

\section{STATE OF MAINE \\ EXECUTIVE DEPARTMENT \\ Maine State Planning Office \\ 38 State House Station \\ Augusta, ME 04333}

Subject: IMPORTANT MEETING - Flood Map Update - Scoping \& Data Collection for Kennebec County

Dear Sir/Madam:

As part of their Flood Map Modernization initiative, the Maine Floodplain Management Program and the Federal Emergency Management Agency (FEMA) will be updating the Flood Insurance Rate Maps (FIRMs) for Kennebec County communities and will be producing a county-wide digital FIRM (DFIRM). In an effort to share information on the flood map update process and provide an opportunity for local input, we would like to meet collectively with the local officials involved in floodplain management from the Kennebec County communities (i.e., code enforcement officers/planners/planning board memeber/GIS staff). We hope for active participation at the meetings, which will help us establish the scope of the mapping project for Kennebec County. Toward that effort, we have mailed this letter to code enforcement officers as well as chief elected officials. Your community's input is very important if you wish to contribute to improving the flood maps. If you choose not to provide input, a new map will still be generated but may or may not reflect changes you would have liked. To accommodate local officials' schedules, both an afternoon and evening meeting have been scheduled. Please use the FAX-back form to confirm attendance at one of the meetings.

\section{Kennebec County: Office of USGS, 196 Whitten Rd., Augusta, Monday, Nov. $7^{\text {th }}, 1-3$ p.m. Kennebec County: Office of KVCOG, 17 Main St., Fairfield, Monday, Nov. $7^{\text {th }}$, 6-8 p.m.}

The State of Maine Floodplain Management Program, the US Geological Survey (USGS) and FEMA or its representative will conduct the Scoping Meetings. The purpose of the meetings is to:

Inform the communities of the nature and the intent of the flood map update process and new digital product,

Make introductions and establish points of contact between the communities, the State of Maine Floodplain Management Program, USGS, and FEMA,

Break into small groups and solicit community input regarding community concerns with the current mapping of the special flood hazard areas (i.e., areas where there is a need for flood elevation data, areas that never flood but are currently mapped in the floodplain and vice versa), 
[Note: the majority of current problems with the base map, such as lack of roads and labelling errors, will be resolved due to use of new aerial photo and digital base map, as explained below]

Identify and prioritize problem areas on current maps (copies will be supplied),

Discuss and record the availability of any community specific data, such as:

o digital orthophotography and (or) topographic mapping data undertaken by the community,

o local flood hazard studies undertaken by the developers, property owners or the community for permitting purposes as required in the local floodplain ordinance OR for the purposes of obtaining a Letter of Map Amendment/Letter of Map Revision from FEMA, any of which provides flood elevation data,

o verified historical data from past flooding events such as surveyed high water marks, photos taken at the time of high water, or post-disaster documents,

0 any community plans for, or interest in, acquiring or contributing to new data

Discuss any changes that have been made to hard structures (culverts, bridges, dams, etc.) within the community that may affect water flow/flooding, or any proposed large developments in the floodplain,

The updated Flood Insurance Rate Maps (FIRMs) will be in a county-wide inclusive format (with many panels), and will be produced in a digital format, known as a DFIRM. The DFIRM will also include an extensive GIS database, and the digital floodplain boundaries will be depicted on an aerial photo base map. The truly digital product will be able to be overlaid on existing GIS base maps of the community/county (i.e. tax map, shoreland zoning map, infrastructure or other GIS based maps), which will improve the use of flood hazard data at the local and regional level. Also, using the new flood map in either paper form or with GIS, will definitely allow for easier and faster flood map determinations.

It is very important that a representative(s) of your community attend one of the Scoping Meetings (the lead floodplain management person - usually the code enforcement officer, the planner/planning board chair, GIS staff, public works director and (or) other involved elected official). It is also important that information regarding the time and place of the Scoping Meeting be disseminated so that anyone who could provide engineering, topographic or mapping data, and is interested in the mapping results, can attend.

To prepare for the Scoping Meeting, we would like for your community to identify flood mapping issues that you would like to be considered for (re)study or review. It would be helpful to have the flooding issues prioritized and be prepared to precisely locate the areas of concern on the flood maps at the meeting. In addition, it would also be very beneficial to bring a brief narrative describing the reasons for the requested (re)studies or reviews. This information will help facilitate the meeting and assist us in finalizing the scope of work. This information may also be sent to the lead scoping agency working in collaboration with the Maine Floodplain Management Program and FEMA: USGS, 196 Whitten Road, Augusta, ME 04330.

Attached with this letter please find a FAX-back sign-up form and maps for the meeting locations. Please submit the FAX-back form by November 3, 2005 so that we can plan accordingly. Your prompt attention to this matter is appreciated, and will help ensure that an accurate and efficient project scope for the flood hazard mapping update for Kennebec County is developed. If you have any questions regarding the Scoping Meetings or desire additional information, please feel free to contact Bonnie at the State Planning Office at 287-8052 or Rob Dudley, from USGS, at 622-8201 ext 115.

Bonnie Cowle, CFM

Maine Map Modernization Project Coordinator
G. Fred Vanderschmidt IV, CFM

FEMA Region I 
Maine Floodplain Management Program

FEMA Map Mod Scoping Meeting Agenda: Kennebec County, Maine

Rob Dudley, P.E.

USGS Maine Water Science Center

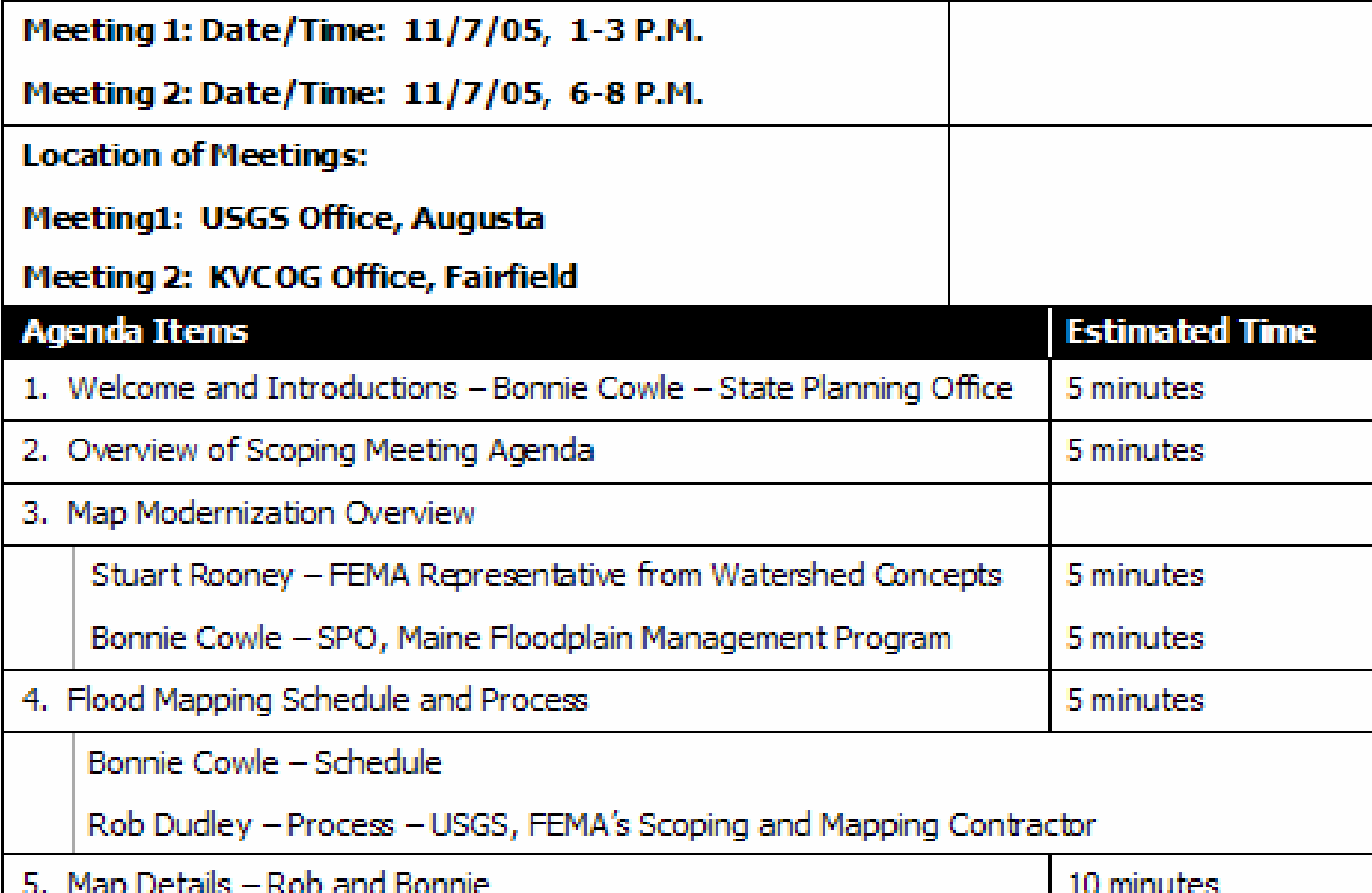

\begin{tabular}{l|l} 
5. Map Details - Rob and Bonnie & 10 minutes
\end{tabular}

Discussion of specific DFIRM issues:

- Map data layers

- Various levels of map detail

- New appearance of DFIRM

- MEGIS orthophoto quad

- Scale and paneling scheme

- Map adoption

- What we need from you

6. Breakout Sessions to Identify Community Mapping Needs $60-90$ minutes

In small working groups with assigned leader:

- Review and comment on USGS/SPO data sheet for your community

- With input from leader complete the community interview form

- Discuss mapping update needs for each community

- Provide rationales for each update needed

- On flood maps, highlight specific areas of need and indicate priorities

7. Turn in Forms \& Maps

Speakers will be available for any final questions 


\section{Kennebec County Community Interview Form FEMA Map Modernization Program November 7, 2005}

\begin{tabular}{l}
\hline Community: \\
CID\#: $\quad \begin{array}{l}230-\ldots- \\
\text { If Town Government, Date of Annual Town Meeting: }\end{array}$ \\
Community Representative(s) attending meeting: \\
Name(s): \\
Title(s): $\frac{\text { EOVT: } \square \text { Town OR } \square \text { council }}{\text { Tel: }}$ \\
Fax: \\
Floodplain Mgt Community Contact (and contact info if different from above):
\end{tabular}

Known problems with flood maps for your community (note FIRM panel numbers)

(Note: Most base-map issues such as street names, roads, corporate boundaries, and spatial issues will be fixed when new digital FIRMS are produced) PLEASE PROVIDE ADDITIONAL INFORMATION FOR ANY YES ANSWERS BELOW

Do you have specific areas that don't flood (1\% chance) but are currently in the floodplain? $\square$ Yes $\square$ No

Do you have specific areas that flood ( $1 \%$ chance) but are not mapped in the floodplain or not mapped at all? $\square$ Yes $\square$ No

\begin{tabular}{l} 
Have any changes in hydraulic structures (bridges, culverts, dams) taken place that would change the maps? \\
$\square$ Yes $\square$ No \\
\hline \\
Do you currently have (or are you proposing) high-development areas where you need new or restudied flood \\
elevations or improved map scale? $\square$ Yes $\square$ No \\
\\
\end{tabular}

\section{Community resources:}

Do you have aerial photography or plans for any (flight date, scale, color/black \& white)? $\quad \square$ Yes $\square$ No

Do you have topographic data or plans for collecting any (digital terrain, contour maps)? $\quad \square$ Yes $\square$ No

Do you have any other data like special hydrologic/hydraulic studies (or plans for studies)? $\quad \square$ Yes $\square$ No

Do you have dedicated GIS capabilities? $\square$ Yes $\square$ No (Provide GIS contact info if different from front page)

Interviewer: Review MNUSS entries and BAD with community rep.

NOTES: 